\title{
Bemerkungen zur Kritik des Kantischen Begriffes des Dinges an sich.
}

Von Anton Thomsen in Kopenhagen.

Das Problem vom Ding an sich oder vielmehr das erkenntnistheoretische Problem von der Beziehung zwischen Subjekt und Objekt, so wie Kant dasselbe gestellt hatte, ist eins der fundamentalen Probleme des Kritizismus, ein Knotenpunkt, wo viele Fäden sowohl der Erkenntnistheorie als der Ethik Kants zusammenstossen. Die Geschichte desselben lässt sich in Kürze in zwei grosse Hauptabschnitte gruppieren. Ende des 18. Jahrhunderts stellte Kant diese Frage in der ihm eigentümlichen Form auf, zum Teil allerdings auf Grundlage der Behandlung derselben von Berkeley, Hume und noch früheren Philosophen, und das gewaltige Aufsehen, welches die kritische Philosophie damals erregte, im Verein mit der grossen Bedeutung, welche Kant selbst dem Problem beilegte, gab den Anstoss zu einer interessanten Diskussion. Die Beiträge von Jacobi, G. E. Schulze, J. S. Beck, Lichtenberg, Reinhold, J. G. Fichte und Maimon erscheinen alle im 18. Jahrhundert und bilden gleichsam einen kleinen abgeschlossenen Abschnitt der Geschichte der Philosophie für sich. Mit dem 19. Jahrhundert tritt eine Bewegung in zweifacher Richtung ein, die auf beiden Seiten von dem Problem vom Ding an sich abführt. Die Romantik schiebt entweder das Problem beiseite oder benutzt Kants Theorie ähnlicherweise, wie er selbst sie in seiner Ethik gebrauchte, als Springstock, um über die Kluft hinweg den Sprung in die Welt der Spekulation zu machen; Schopenhauer bedient sich derselben als Grundlage für die Metaphysik des Willens, und Carlyle auf eine dem Kritizismus noch ferner stehende Weise zur Stütze für seine Theologie und für die „Philosophie der Kleider". Anderseits nimmt der Materialismus das Problem nicht in dessen Gesamtheit, sondern löst einen Teil desselben dogmatisch, zerreisst 
hierbei die fein verschlungenen Fäden gewaltsam und macht eine wirklich eingehende und allseitige Behandlung des Problems zur Unmöglichkeit.

Die zweite Hauptphase des Problems tritt in der letzteren Hälfte des 19. Jahrhunderts mit dem Neu-Kritizismus ein; die auf Kant zurïckführende Bewegung bewirkte grösseres Verständnis der Wichtigkeit des Problems und ein Interesse, es wieder auf Kants Weise zu stellen und die Richtigkeit und Tragweite seiner Lösung zu untersuchen. Es ist hier nun die Aufgabe, den Nachweis zu versuchen, dass Kants Lösung unrichtig ist, dass dieselbe auf einer Verwechselung beruht, dass sie sein System untergräbt, wie auch geschichtlich den Grund darzulegen, weshalb die Verwechselung sich ins. System einschlich, zugleich aber in enger und notwendiger Verbindung hiermit zu zeigen, dass es dem Neu-Kritizismus nicht gelungen ist, Kant vor den Einwürfen, die im 18. Jahrhundert gegen seine Theorie von der Beziehung zwischen Subjekt und Objekt gerichtet wurden, zu schützen.

Mit seiner Theorie glaubt Kant nicht nur selbst auf dem Boden des Realismus zu stehen, sondern auch sowohl den skeptischen als den dogmatischen Idealismus widerlegt $\mathrm{zu}$ haben. Kant nennt seinen eignen Standpunkt den transscendental-idealistischen und meint, dieser lasse sich sehr wohl mit dem empirischrealistischen vereinen. Um Kant $\mathrm{zu}$ verstehen, wird es zweckmässig sein, diese verschiedenen Auffassungen der Beziehung zwischen Subjekt und Objekt in Kürze' zu betrachten und ihren Wert zu prïfen. Es sei der Ausgangspunkt, dass ich etwas sehe, etwas denke, etwas fühle: es ist dann klar, dass wir uns einer Reihe von Zuständen gegenüber befinden; wir können hierbei stehen bleiben, uns damit begnügen, dieselben zu beschreiben und uns entschieden weigern, weiter zu gehen, bestreiten, statt der Beschreibung eine wirkliche Erklärung geben zu können. Wir sind dann zunächst in dem Bereiche dessen, was Kant den skeptischen Idealismus nennt, den er durch Descartes' „cogito ergo sum" ausdriickt. , Der Ausdruck ist kein geeigneter, denn der konsequente Idealist würde, wie wir später sehen werden, den Idealismus in Kants Redaktion nicht anerkennen, da schon in dem Cartesischen Satze zwei Postulate, oder, sofern der Satz tautologisch aufzufassen ist, jedenfalls ein Postulat liegt. Schon Lichten- 
berg $\left.{ }^{1}\right)$ sagt: „Wir werden uns gewisser Vorstellungen bewusst, die nicht von uns abhängen; andere glauben wir wenigstens hingen von uns ab; wo ist die Grenze? Wir kennen nur allein die Existenz unserer Empfindungen, Vorstellungen und Gedanken. Es denkt, sollte man sagen, so wie man sagt: es blitzt. $\mathrm{Zu}$ sagen: cogito, ist schon zu viel, sobald man es durch Ich denke übersetzt."

Der konsequente Idealismus ist, wie Lichtenberg dies klar sagt, unwiderleglich. Derselbe giebt aber keine Erklärung, und deswegen muss man, wenn man überhaupt weiter will, einen Sprung unternehmen. Dieser Sprung kann nach zwei Seiten geschehen. Ist der konsequente Idealismus gleich unwiderleglich, so enthält er doch eine Schwierigkeit, der er sich nur dadurch zu entziehen vermiag, dass er immer wieder entschieden verweigert, eine Erklärung zu geben, die Schwierigkeit nämlich, dass es, selbst wenn sich keine scharfe Grenze ziehen lässt, sogar im Bewusstsein des konsequenten Idealisten deutlich genug zwei Gruppen von Elementen giebt, die an einigen Punkten auseinander divergieren, ob sie sich sonst auch ähnlich sind, und diese beiden Gruppen können wir ohne Antizipation die mehr objektiven und die mehr subjektiven Zustände nennen. Das Kriterium mag einstweilen gleichgültig sein; um sich keines Übergriffes schuldig zu machen, kann man Benekes guten und vorsichtigen Ausdruck benutzen und das den Unterschied Bedingende "das Gefühl der Urfrische" ${ }^{2}$ ) nennen; hierdurch wird der Unterschied zwischen Empfindung und Vorstellung am kürzesten ausgedrückt. Dieser Unterschied erheischt eine Erklärung, der konsequente Idealismus weigert sich aber, die Erklärung dieser Urthatsache zu geben. Man kann sich nun an den dogmatischen Idealismus wenden, der in Kants Augen von Berkeley vertreten wird. ${ }^{3}$ ) Derselbe legt dem Unterschied

1) Vermischte Schriften. 1801. II., S. 95.

2) Psychologische Skizzen. 1825. I. S. 72 u. f.

3) Ich bitte zu beachten, dass ich mich der Begriffe nicht ganz so wie Kant bediene. Der konsequente Idealismus ist bei Kant unter zwei Formen anzutreffen, als "skeptischer" und als "dogmatischer"; ersterer bezweifelt, letzterer leugnet das Recht, weiter zu gehen. Berkeley ist in Kants Augen der dogmatische Idealist, und so würde ich ihn auch bezeichnen, indem ich unter dem dogmatischen Idealismus diejenige Richtung verstehe, welche eine Erklärung giebt, mithin weiter geht, welche aber das Subjektive zum Letzten und Fundamentalen macht. Diese nennt Kant den "Spiritualismus" oder den "Pneumatismus". Unter dem naiven Realismus verstehe ich diejenige Richtung, welche die Ding 
keine Bedeutung bei, muss diesen zuguterletzt konsequent aber eigentlich übersehen, denn alles rührt von derselben Quelle her. Eben wegen dieser Behauptung ist der dogmatische Idealismus somit melır entgegenkommend als der skeptische, da er eine Erklärung zu geben wünscht. Dennoch wird man getäuscht, denn in der That verwehrt er nur jegliche Erklärung; was im skeptischen Idealismus Vorsicht und einfache Verneinung war, wird im dogmatischen zum gewagten Postulat, das in der That nur eine verhehlte Vermeinung ist, indem der dogmatische Idealismus sofort einen durchaus unbekannten Faktor einführt, der ausser stande ist, eine wirkliche Erklärung zu enthalten. Bei Berkeley wird dieser letzte Faktor der Begriff "Gott", nach Kant trifft man in der Philosophie der Romantik einen ähnlichen in J. G. Fichtes „transscendentalem Ich“ an; bei beiden ist die Grenze der Erfalrung iiberschritten, der dogmatische Idealismus hat sich als eine Art Pantheismus des Subjektes entpuppt. Die Erkenntnistheorie hat, wenn sie auf streng wissenschaftlichem Boden fussen will, nur eins zu thun, nämlich demjenigen, der „das Gefühl der Urfrische", diesen Unterschied zwischen Empfindung und Vorstellung verneint oder zu erklären verweigert, die Beweislast aufzuerlegen. Demnach giebt es die Möglichkeit, einen anderen Weg einzuschlagen, der sich als die Richtung von aussen nach innen bezeichnen lässt, während der dogmatische Idealismus den Weg von innen nach aussén $\mathrm{zu}$ betreten versuchte. Man -kann vorerst ohne

des Raumes, so wie sie erscheinen, das Objektive sein lässt, unter dem R e a lis mus diejenige, welche diese Dinge reduziert und das Objektive in der Welt der Phänomene als ein von dem Subjektiven Verschiedenes zu bestimmen sucht, also dasselbe, was Kant den „empirischen Realismus" nennt. Unter dem dogmatischen Realis mus verstehe ich diejenige Richtung, welche das objektive Substrat des Realismus zu dem Letzten und alles Begründenden macht, also Kants "Materialismus". Wenn ich Kants Bezeichnungen nicht gebrauche, so liegt dies erstens darin, dass ich Kants Sonderung zwischen dem skeptischen und dem dogmatischen Idealismus keine grosse Bedeutung beilege, zweitens darin, dass Kants Unklarheit in betreff des Begriffes des Dinges an sich gerade zu einer Abänderung seiner Bezeichnungen bewegen muss. Kant ist seiner Raumtheorie zufolge, was er einen "transscendentalen Idealisten" nennt, das Wort "Idealist" ist hier aber irreführend, oder vielmehr es weist auf einen Fehlschluss von seiten Kants hin; zugleich ist er „empirischer Realist", wird aber schliesslich, so wie seine Theorie vom Ding an sich gestaltet wird, zum dogmatischen Idealisten - nicht in seinem eignen, wohl aber im hier aufgestellten Sinne. 
weiteres die Empfindungen mit den Dingen idèntifizieren - das ist der naive Realismus. Selbstverständlich ist er unhaltbar, an diesem Punkte erhebt sich die Frage aber in einer neuen und besseren Forn, sie wird richtiger gestellt, indem nicht wie vorher nach einer letzten begründenden Substanz, sondern nach dem in der Erfahrung Gegebenen gefragt wird; das Problem heisst nicht: Subjekt - oder Objekt, sondern dreht sich um die Beziehung zwischen Subjekt und Objekt.

Schon Demokrit stürzte den naiven Realismus d durch seine Lehre von der Subjektivität der Sinnesqualitäten, durch seine Entwickelung des doppelten Prozesses aus Subjekt in Objckt und aus Objekt in Subjekt und durch seine Bestimmung der Atome. Diese Lehre wurde. näher ausgeformt; obschon die einzelnen näheren Bestimmungen bei den verschiedenen Forschern Galilei (Gestalt, Grösse, Bewegung und Ruhe), Descartes (Gestalt, Grösse, Bewegung und Lage) und Locke (Gestalt, Ausdehnung, Bewegung und Dichtigkeit) Verschiebungen erleiden, bleibt das Prinzip doch durchweg dasselbe. Dieses besteht darin: innerhalb der Erfahrung das mehr Subjektive von dem mehr Objektiven zu sondern und durch möglichst genaues Abgrenzen jedes derselben zugleich ihr gegenseitiges Verhältnis zu bestimmen zu suchen. Aus dem Folgenden wird hervorgehen, dass der Standpunkt, der in betreff des 18. Jahrhunderts am klarsten durch Locke vertreten ist, mit Bezug auf das vorliegende Problem als der fruchtbringende und als der einzige $\mathrm{zu}$-betrachten ist, von welchem aus man die Sache anfassen muss, um auf einen IVeg zu gelangen, der wirklich rorwärts führt, während Berkeleys Theorie ein Sprung zur Seite ist und selbst Hume die Sache verkehrt anfasst. 1) Geht man diesen von Demokrit, Epikur, Gassendi, Galilei, Descartes, Hobbes und Locke angegebenen Weg, so wird.man dahin gelangen, dass man als das Objektive den Raum und die in diesem wirkende Kraft hat, wie man nun die Ausdrücke der verschiedenen Forscher unter diese verschiedenen Begriffe verteilen möge. Schliesslich stehen wir dann auf dem Standpunkte, dass unsere Empfindungen Stössen von Gegenständen, Luftwellen, ت̈therschwingungen u. s. w. zu verdanken wären. Möglicherweise liessen diese objektiven Substrate - und eben um diese handelt sich das Problem der Materie - sich auf den Begriff der Energie reduzieren; es leuchtet aber

1) Treatise. ed. Selby-Bigge. S. 187-251, besonders S, 225-231. 
ein, dass wir hicr entweder an das denken müssen, was wir selbst als Widerstandskraft kennen, oder dass wir uns an dasselbe nur als an eine letzte unbekannte Grösse halten müssen, mit welcher wir rechnen - wenn es überhaupt möglich ist, mit derselben zu rechnen. lis ist indes klar, dass dieses objektive Substrat phänomenal im Kantischen sinne des Wortes ist, zugleich ist es aber objektiv im Vergleich mit etwas anderem, das mehr subjektiv ist.

In Kants Welt der Erscheinungen giebt es also eine Sonderung zwischen dem objektiven Substrat, das aus Grössen besteht, mit denen man rechnen muss, und einem anderen, dem subjektiven, von welchem man dabei willkürlich absieht. Man hat hier die Grenze auf zweifache Weise, subjektiv, weniger klar, zugleich aber in weit grösserer Ausdehnung, mittels Selbstbeobachtung in dem Unterschied zwischen Empfindung und Vorstellung - objektiv, gleichsam in einer anderen Dimension und als mehr spezielles und begrenztes Problem dort, wo der physisch-physiologische Vorgang in einen Bewusstseinszustand übergeht, und hier scheint die Grenze auf alle Zeiten unïbersteiglich $\mathrm{zu}$ sein. Unseren Empfindungen entspricht also das objektive Substrat, nicht so wie der naive Realismus meint, sondern so, dass es unsere Empfindungen verursacht, hier ganz davon abgesehen, was es schliesslich sein mag (das Problem der Materie), oder wie gross die Tragweite seiner Wirkungen sein kann (das Problem vom Verhältnisse zwischen Geist und Materie). Es ist notwendig, diese objektiven Grössen in der Wissenschaft anzuwenden, wir müssen stets mit denselben rechnen, selbst wenn wir von einem streng erkenntnistheoretischen Gesichtspunkt aus gewahren, dass wir hier dasjenige Grundpostulat aufstellen, welches in jeder Kausalerklärung enthalten ist, und zugleich in der Praxis von verschiedenen Faktoren absehen; und unsere Bemühungen müssen darauf ausgehen, diese Grössen möglichst weit zụrïckzuführen und uns des Umfanges ihrer Tragweite bewusst zu werden. Diese Grössen oder das objektive Substrat, das also innerhalb der Kantischen Welt der Erscheinungen liegt, werde ich das positive oder das empirische Ding an sich (Ph-O) nennen, und sein wirklicher Gegensatz ist das Subjektive innerhalb der Welt der Erscheinungen (Ph-S) ').

1) Es muss hier gleich bemerkt werden, dass Kant das objektive Substrat eigentlich nicht das Ding an sich nennt. Die Bestimmungen desselben werden aber mit in den Begriff des Dinges an sich hineingezogen, und eben hierin besteht die Grundverwechselung. Kants Bezeich- 
Den anderen Begriff, der sich in Kants theoretischer Philosophie unter dem Ausdruck „Ding an sich" verbirgt, werde ich im Gegensatz zum empirischen das negative oder das transscendentale Ding an sich nennen (nach Kants eigener Terminologie wäre es, wenn wir das empirische als $\mathrm{Ph}-\mathrm{O}$ bezeichnen, $O$ zu benennen). Kant hat dieses transscendentale Ding an sich besonders, in der "Analytik der Grundsätze" unter der Überschrift „Phänomena und Noumena“ entwickelt. ${ }^{\text {) }}$ Kants Gedankengang ist hier folgender: All unsere Erkenntnis ist phänomenal, denn unter Erkenntnis verstehen wir Wahrnehmung unter den Formen der Sinnlichkeit, nämlich Raum und Zeit, und Denken unter den Formen des Verstandes, den Kategorien, und alle diese Formen sind subjektive, spezielle Formen der grossen. Grundform des Subjekts, nämlich der Einheit oder Synthese des Bewusstseins. Von der Richtigkeit der Prämissen abgesehen wird das Resultat für Kant, dass jede Erkenntnis subjektiv ist. Dies ist so klar und so selbstverständlich wie nur irgend möglich; dass ein Ding erkannt wird, oder dass es ist, will heissen, dass es für ein Subjekt ist, und weiter gar nichts; Dingen, die sich nie direkt oder indirekt erkennen lassen, ein Dasein beizulegen, ist unberechtigt. Subjekt und Objekt sind Korrelate, im Begriffe der Erkenntnis, im Begriffe des Objekts liegt schon das subjektive Moment - ohne Subjekt kein Objekt, ebensowenig wie Erkenntnis ohne erkennendes Subjekt. Steht es nun aber ebenso unerschütterlich fest, dass jede Erkenntnis subjektiv ist und nur Erscheinungen betrifft, wie dass niemand über seineu eigenen Schatten hinweg-

nungen des empirischen Dinges an sich sind verschieden, wir finden dasselbe dargestellt unter Ausdrücken wie Stoff, Materie, äussere Gegenstände des Raumes, die Aussenwelt, empirische Objekte, Sachen an sich selbst. Diese verschiedenen Wörter bezeichnen in Wirklichkeit verschiedene Nüancen desselben Begriffes, was teils auf ungenügender Analyse ron seiten Kants beruht, teils sich nach dem Zusammenhang richtet, in welchem sie vorkommen; um Missverständnissen vorzubeugen, habe ich diese Bezeichnungen vermieden und im Anschluss an das zuletzt genannte Wort den Begriff des "empirischen Dinges an sich" gebildet. Die ganze Ablandlung sollte zeigen, dass diese Wortbildung, gewissermassen als ein Symbol der Grundverwechselung bei Kant, berechtigt ist. Auch Vaihinger hat die Bezeichnung "Dinge an sich selbst im empirischen Verstande". (Strassburger Abhandlungen zur Philosophie 1884. S. 150. Vgl. Kritik der reinen Vernunft. Kehrbachs Ausg. S. 57, vgl. S. 315 u. f.)

1) Krit. d. rein. Vern. S. 221 u. f. 
zuspringen vermag, so ist es klar, dass in dieser Bestimmung eine Grenze liegt; eben dic Natur der Firkenntnis gicbt der Erkenntnis ihre Grenze; eben weil alle Erkenntnis subjektiv ist und Erscheinungen betrifft, wird nan nie bestreiten können, dass etwas ausserhalb der Erkenntnis sein Dasein habe, dass es ein Objekt ohne entsprechendes Subjekt geben könne, wenn die Bezeichnung "Objekt" dann auch als sich selbst widerstreitend zu betrachten wäre. Diese absolute Grenze der menschlichen Erkenntnis ist das transscendentale Ding an sich; sie ist rein negativ, denn sie sagt nur: $\mathrm{Ob}$ ausser den Erscheinungen, die für uns - wenigstens in Bezug auf Kants theoretische Philosophie - alles sind, noch etwas anderes existiert, davon können wir nichts wissen, noch weniger natürlich wissen, was dies andere sein könnte. Anderseits dürfen wir nicht dogmatisch bestreiten, dass noch andres sein könne, gerade weil wir dann, ebensowohl wie wenn wir sagten, es sei anderes, die Grenze der Erkenntnis überschreiten würden, welche Grenze dadurch gegeben ist, dass alle Erkenntnis phänomenal ist, dass ein Objekt ohne ein Subjekt kein Objekt ist. Oder wie Kant vom transscendentalen Ding an sich sagt: „dieses bedeutet eben den problematischen Begriff von einem Gegenstande für eine ganz andere'Anschauung und einen ganz anderen Verstand als den unsrigen, der mithin selbst ein Problem ist". ${ }^{1}$ ) Dass das ausserhalb der Grenze der Erkenntnis Liegende zum Objekt, d. h. zur Erscheinung im Kantischen Sinne für eine ganz andere Erkenntnis als die unsrige werden kann, lässt- sich vernunftgemäss niemals bestreiten; wer aber behaupten will, es existiere solches, muss vorher die Natur dieser Erkenntnis erklären; obschon diese Aufgabe eben der Natur unserer Erkenntnis zufolge als hoffnungslos zu betrachten ist, darf man die Möglichkeit, dass eine solche Entwickelung gegeben werden könnte, selbstredend nicht a priori bestreiten, solange sie aber nicht gegeben wird, ist alle menschliche Wissenschaft und alles menschliche Interesse an die Welt der Erscheinungen und nur an diese allein geknüpft.

Man kann hier Kant mit Spinoza vergleichen, wenn letzterèr sagt, Gott besitze ausser den beiden bekannten Attributen unendlich viele andere, die unserer Erkenntnis unzugänglich seien. ${ }^{2}$ ) Das transscendentale Ding an sich sagt: es ist sehr wohl möglich, dass

1) Kr. d. r. V., S. 257, vgl. 236.

2) Ethica. I. Prop. 11. 
ausserhalb der menschlichen Erkenntnis noch mehr existiert, wir wissen aber nichts hierüber und dürfen es deshalb weder dogmatisch bejahen noch verneinen. Das transscendentale Ding an sich als die äusserste Grenze der Erkenntnis, als der bis zum letzten Augenblick fortgesetzte Protest der Erkenntnis gegen jeden Dogmatismus, als die Selbstverneinung der Erkenntnis, um, wo diese endet, jede unberechtigte Behauptung zu vermeiden, besitzt ausser der Bedeutung, die es für die Geschichte der Philosophie hatte, dass die Grenze gezogen wurde - nicht mehr Interesse als Spinozas unbekannte Attribute, d. h. eigentlich gar keines. Wir interessieren uns bei Spinoza für Geist und Materie, bei Kant für die phänomenale Erkenntnis und deren Grenze oder vielmehr dafür, wo die Grenze liegt. Die Grenze ist aber mit der Natur der Erkenntnis dadurch gegeben, dass alles Erkennen subjektiv ist, und das transscendentale Ding an sich ist weiter nichts als der letzte unlösbare Zweifel der Erkenntnis, dasselbe sagt nur negativ, was positiv dadurch ausgedrïckt wird, dass alle Erkenntnis phänomenal ist. „Reine Objekte“, „Objekte“, die nicht für unsere Erkenntnis existieren, haben durchaus kein Interesse für uns, liegen uns ebenso fern wie Spinozas postulierte unbekannte Attribute; Interesse hat das transscendentale Ding an sich nur negativ, wo es dogmatische Behauptungen von dem Unerkennbaren bekämpft, indem es dafür eintritt, dass das Unerkennbare unerkennbar und weiter nichts ist.

Dies ist das transscendentale Ding an sich, und in der folgenden Darstellung wird es in verschiedenem Zusammenhang versucht werden, diesen Begriff genauer $\mathrm{zu}$ präcisieren und näher zu beleuchten, indem wir von den verschiedenen Gesichtspunkten ausgehen, die durch diejenigen Punkte gegeben sind, an welchen die Verwechselung zwischen demselben und dem empirischen Ding an sich bei Kant eintritt. Denn diese Darstellung sollte darthun, wie die Schwierigkeit mit Kants Ding an sich darauf beruht, dass er zwei so weit verschiedene Sachen, das empirische und das transscendentale Ding an sich, das der Erkenntnis äusserer Erscheinungen zu Grunde Iiegende und eben die Negation der Erkenntnis, mit einander verwechselt hat, und wie das Verständnis von Kants Entwickelung des Problems von dem Verhältnisse zwischen Subjekt und Objekt nur daun möglich ist, wenn man von dieser Hypothese ausgeht. Es ist völlig beweislich und sicher, dass die Bestimmungen sowohl des empirischen als die 
des transscendentalen Dinges an sich unter der Bezeichnung „Ding an sich" oder "Noumenon" in der "Kritik der reinen Vernunft" sehr deutlich und zwar unmittelbar nebeneinander angetroffen werden, und es ist nun klar, dass meine Hypothese auf zweifache Weise verifiziert wird - und nur so verifiziert werden kann, da jede Weise erforderlich ist und die andere ergänzt: teils indem ich darlege, wie Kant geschichtlich während seiner Entwickelung zum definitiven Standpunkte auf deutliche und natürliche Weise zur Verwechselung gefïhrt wurde, teils indem ich nachweise, wie die Bestimmungen beider Begriffe, des transscendentalen und des empirischen Dinges an sich, im definitiven System mit einander streiten und - wie zu erwarten steht - Widersprüche und unrichtige Resultate erzeugen, weil sie nicht auseinandergehalten wurden. Endlich eröffnet diese Hypothese den Weg zum klareren Verständnisse mehrerer dunklen Punkte in Kants praktischer Philosophie, sowohl während der letzten Phase der Geschichte der eigentiimlichen ethischen Entwickelung Kants als auch in definitiven System. Die meisten Kantforscher gingen von der Hypothese aus, Kants Ding an sich sei ein einzelner Begriff und Kant müsse recht haben, und dies hat wieder eine Reihe phantastischer Hypothesen und misslungener Rettungsversuche ins Leben gerufeu, deren gegenseitige Widerlegung den Forscheru grossen Scharfsinn gekostet hat. Als Supplement meiner Verifikation werde ich endlich in Kürze die wesentlicheren dieser Rettungsversuche im Nelt-Kritizismus betrachten und zeigen, wie unhaltbar dieselben sind, indem ich mich bei diesen Widerlegungen also zum Teil auf die Kritik der Mitapologeten stütze.

Um zu verstehen, wie die Grundverwechselung bei Kant geschichtlich entstanden sein kann, ist es notwendig, auf die Dissertation von 1770 zurückzugehen. Kant unterscheidet hier zwischen einer realen und einer phänomenalen Welt; Raum und Zeit sind subjektive Anschauungsformen, und alles, was man unter diesen auffasst, wird zur Erscheinung. Mittels des Verstandes erkennen wir dagegen die Dinge an sich, die Noumena. ${ }^{1}$ ) Das Noumenon

1) Dissertation § 3-6. Von Forschern wie Kuno Fischer und Emil Arnoldt ("Kant nach Kuno Fischers neuer Darstellung". 1882. S. 24 u. f.) wurde behauptet, es sei nicht Kants Meinung in der Dissertation, dass wir eine Erkenntnis des Dinges an sich hätten. Sie geben in- 
als rationaler Faktor beschränkt also den empirischen Faktor, „die Anmassung der Sinnlichkeit". Die Sinnlichkeit kann nicht alles erreichen, das Höchste, die eigentliche Realität bleibt dem Verstande vorbehalten. Es ist nun klar, dass der Begriff des Noumenon sich von zwei Gesichtspunkten aus betrachten lässt. Als einer (möglichen oder wirklichen) Verstandeserkenntnis korrespoudierend ist er das alles in der Welt Begrïndende, und abgesehen von der Natur der Verstandeserkenntnis und von Kants Unsicherheit an diesem Punkte der Dissertation steht es ganz zweifellos fest, dass Kant unter dem Begriffe des Noumenon das Reale, Objektive und Feste versteht, das, was hinter den Erscheinungen liegt, selbst wenn Kant vielleicht schon hier meinen möchte, es liege etwas höher, als die alte Metaphysik glaubte. In engem $\mathrm{Zu}$ sammenhang hiermit wird, mit dem platonischen Dualismus der Dissertation vor Augen, der Begriff des Noumenon zugleich ein Grenzbegriff; dersclbe ist nämlich die Grenze der Sinnlichkeit, indem er deren Anmassung beschränkt. Zugleich ist es aber klar, dass Grenze hier einen anderen Sinn hat als bei dem transscendentalen Ding an sich. Hier ist die Grenze eine positive, die Scheide zwischen zwei wirklichen Welten, der phänomenalen und der intelligibeln. Im transscendentalen Ding an sich ist das Ding an sich seit 1770 so eingeschwunden, dass es statt eines begrenzenden Landes zur blossen Grenze, oder vielmehr nur zur Grenze für die Anmassung der Erkenntnis wird, dass es an der äussersten Grenze der Erkenntnis zum Verhüter jeder dogmatischen Behaup-

des zu, dass die Grenze zwischen Erscheinung und Ding an sich sehr unsicher ist, was dem Anschein nach zu der Konsequenz führen müsste, dass auch zwischen der Erkenntnis der Erscheinung und der problematischen Erkenntnis des Dinges an sich nur ein gradueller Unterschied stattfände. Ich glaube jedoch, indem ich mich namentlich auf die von Erdmann herausgegebenen "Reflexionen Kants" stütze, die Behauptung wagen zu dürfen, dass Kant 1770 wirklich die Möglichkeil einer rationalen Metaphysik und einer Erkenntnis des Dinges an sich aufstellt. (Vgl. Höffding: „Die Kontinuität im philosophischen Entwickelungsgange Kants“. Arch. f. Geschichte der Philosophie. VII. S. 187. Riedel: „Die monadologischen Bestimmungen in Kants Lehre vom Ding an sich“. 1884. S. 6-9, und Fr. Paulsen: "Immanuel Kant". 1898. S. 88 u. f.). Selbst wenn Fischer und Arnoldt aber recht hätten, so ist es doch klar, dass der Begriff des Dinges an sich oder des Noumenon in der Dissertation ein positiver Begriff ist und etwas sehr Reales, eigentlich das Allerrealste bezeichnet, einerlei, in welchem Grade es zu erkennen sein möchte. Und mehr ist für unsere geschichtliche Erörterung nicht von nöten. 
tung an diesem Orte wirl. Hiermit steht es in Verbindung, dass das Subjektive, Pläuonıeuale, das in der Dissertation nur für die Sinnlichkeit Gültigkeit besitzt, in der Kritik der reinen Vernunft so erweitert ist, dass es fiir alle Erlienntnis iiberhaupt Gültigkeit hat. In dem Satze: All unsere Erkenntnis ist phänomenal, müssłe in der That das Ding an sich der Dissertation wegfallen, nicht nur als positiver Begriff, sondern auch zugleich als wirklicher Grenzbegriff.

Wir worden später auf den Begriff der Grenze zurïckkommen, von aller Doppelheit und allen Schwierigkeiten desselben abgesehen leuchtet es aber ein, dass es äusserst unzweckmässig ist, die letzte Grenze der Erkenntnis, das Negativste von allem durch den Begriff des Dinges an sich zu bezeichnen, der den Gedanken ganz natürlich auf etwas Begründendes, auf das Objektivste von allem in der Welt lenken muss. Bezeichnungen sind gleichgültig, wenn nur die Definitionen klar sind, die Geschichte der Philosophie hat aber oft gezeigt, wie grossen Schaden irrefïhrende Bezeichnungen anstiften können, und Kants Begriff des Dinges an sich ist eins der typischsten Beispiele von der Macht des leeren Wortes; denn nachdem der Dualismus der Dissertation hinsichtlich der theoretischen Philosophie aufgegeben war, wurde das Ding an sich in der That ein leeres Wort. In der Dissertation hatte es sehr guten Sinn, die Bezeichnung "Noumenon“ oder "Ding an sich" zu gebrauchen, ganz sinnlos ist es aber, dieselbe in Kontinuität der Dissertation in der Kritik der reinen Vernunft beizubehalten, denn in der Zwischenzeit war gerade erzielt: dass der Begriff des Dinges an sich entweder als empirisches Ding an sich in die Welt der Erscheinungen hineingezogen oder auch als ein absolut negativer Begriff, als Negation eben der Erkenntnis beibehalten werden müsste. Für letzteres, für das problematische Objekt einer ganz anderen Anschauung und eines ganz anderen Verstandes, als wir besitzen, die also beide selbst problematisch sind, ist die Bezeichnung ,.Ding an sich" so inkorrekt: und so irreführend, wie nur irgend eine Bezeichnung es sein kann. Dennoch behält Kant sie bei, thut es aber nur, weil er das transscendentale mit dem empirischen Ding an sich verwechselt, und verwechselt diese, weil er sich in der That das transscendentale Ding an sich niemals klar zurecht gelegt hat, weil er den Satz: alle Erkenntnis ist phänomenal, niemals in allen Konsequenzen durchgeführt hat. Hinter Kants kritischer Philosophie liegt eine 
wie Leibniz' Monaden, und Kant denkt sich in der That diese als die Welt der Erscheinungen begründend.1) In den Reflexionen finden wir dieselben Bezeichnungen wie in der Kritik der reinen Vernunft, der metaphysische Hintergrund ist hier deutlich zu erblicken, und eben die Unklarheit ist charakteristisch, denn gerade diese ermöglicht die Verwechselung in der Kritik der reinen Vernunft.

Die wirkliche Verifikation der Hypothese erfordert den Nachweis, dass im Worte Ding an sich das empirische und das transscendentale Ding an sich in Kants kritischem Systeme miteinander vermengt werden. Der 'erste hier hervorzuhebende Punkt ist Kants Polemik gegen den Idealismus. In der Dissertation ist Kants Stellung klar und mit seinem ganzen platonischen Dualismus gegeben. Er äussert sich gegen den Idealismus von dem Standpunkt aus, dass es ausserhalb der Welt der Erscheinungen Dinge an sich gebe, welche dieselbe begründeten. Diese Auffassung spaltet sich nun auf sonderbare Weise. Da Kant nach der Dissertation auch die intelligihle Welt phänomenal macht, muss dies hier €ine Änderung seiner Anschauungen bewirken. Das Ding an sich lässt sich nicht mehr erkennen und tritt deshalb zurück, obschon es fortwährend im Hintergrunde bleibt. In der Welt der Erscheinungen muss nun zwischen dem Objektiven und dem Subjektiven genauer gesondert werden, d. h. Kants Interesse kehrt sich speziell diesem Punkte zu, in natürlicher Verbindung mit der Entwickelung seines eigenen "transscendentalen Idealismus:", während anderseits das transscendentale Ding an sich (O) als unerkennbar dennoch fortbesteht und hinter dem empirischen funktioniert, obschon es nicht in die Polemik gegen den Idealismus hineingezogen wird.

Im vierten Paralogismus ${ }^{2}$ ) ist der Gedankengang folgender. In der Welt der Erscheinungen, sagt Kant, müssen wir zwischen subjektiven Zuständen und dem objektiven Substrat unterscheiden. Man könnte die Sache so aufstellen: meine Empfindungen kenne ich unmittelbar, das objektive Substrat in der Welt der Erscheinúngen mittelbar durch Schliessen, indem ich also aus dem Innern

1) Refl. 1149 (S. 328), Refl. 1128 (S. 322), Refl. 1155 (S. 330) und Erdmanns Note S. 323.

2) Krit. d. r. V. (Kehrbach), S. 311-321. 
auf ein Äusseres als dessen nächste Ursache schliesse. Der skeptische Idealist meint, dieser Schluss sei unsicher, Kant meint aber, dies lasse sich nur von der falschen Auffassung aus behaupten, lasss las objektive Substrat (Ph-O) ausserhalb der Welt der Erscheinungen liege, also als transscendentales Ding an sich (O). I)ie Hauptsache ist nach Kant aber die, dass gar kein Schluss stattfindet; fïr ilhn steht in der That das Dasein äusserer Erscheinungen rein unmittelbar fest und zwar mit derselben Sicherheit wie das Dasein des eigenen Selbst. „Also ist der transscendentale Idealist ein empirischer Realist und gestehet der Mraterie, als Erscheinung, eine Wirklichkeit $\mathrm{zu}$, die nicht geschlossen werden darf, sondern unmittelbar wahrgenommen wird“."1) Kant gelangt mithin zu dem bestimmten Resultate, dass innerhalb der Welt der Erscheinungen etwas Wirkliches im Raume unserer äusseren Wahrnchmung entspreche. ${ }^{2}$ ) Dies ist klar ausgedrückt das empirische Ding an sich, wenngleich Kant das Wort nicht darauf anwendet. Gegen den skeptischen Idealismus, der sich zum empirischen Ding an sich zweifelnd verhält und die Richtigkeit des Schlusses auf lasselbe bestreitet, äussert Kant sich folgendermassen: „Den empirischen Idealismus, als eine falsche Bedenklichkeit wegen der objektiven Realität unserer äusseren Wahrnehmungen zu widerlegen, ist schon hinreichend: dass äussere Wahrnehmung eine Wirklichkcit im Raume unmittelbar beweise, welcher Raum, ob er zwar an sich nur blosse Form der Vorstellungen ist, dennoch in Ansehung aller ${ }^{3}$ ) Erscheinungen (die auch nichts anderes als blosse Vorstellungen sind) objektive Realität hat; imgleichen; dass ohne Wahrnehmung selbst die Erdichtung und der Traum nicht möglich siud, unsere äusseren Sinne also, den Datis nach, woraus Erfahr'ung entspringen kann, ihre wirklichen korrespondierenden Gegenstände im Raume haben." Obschon es einleuchtet, dass der Bewcis gegen den skeptischen Idealisten verfehlt ist, da wir zu dem empirischen Ding an sich wirklich mittels eines Schlusses gelangen, dessen Berechtigung sich bezweifeln lässt, oder vielmehr, wie friiher entwickelt, durch das Unternehmen eines Sprunges, der gemacht werden muss, wenn wir überhaupt weiter kommen und eine

1) S. 314 .

2) S. 318 .

8) Benno Erdmann hat hier in seiner Ausgabe nach „aller" das Wort "ïusseren" (S. 631), ebenfalls Hartenstein (2. Aufl., S. 603) und Adickes (S. 507). 
wissenschaftliche Erklärung geben wollen, so müssen wir doch behaupten, dass Kants Sonderung hier sowohl berechtigt als sehr bedeutungsvoll ist. ${ }^{1}$ )

Neben dem empirischen tritt hier aber auch das transscendentale Ding an sich auf. Kant meint, wenn er sage, alles sei subjektiv, so verliere diese Äusserung das Anstössige, sobald man bedenke, dass er nur von Erscheinungen und nicht von Dingen an sich rede. Mit grosser Deutlichkeit wird dieser Begriff im Gegensatz zum empirischen Ding an sich aufgestellt. „Nun kann man zwar einräumen, dass von unseren äusseren Anschauungen etwas, was im transscendentalen Verstande ausser uns [d. h: nicht im Raume, sondern ausserhalb der Welt der Erscheinungen] sein mag, die Ursache sei, aber dieses ist nicht der Gegenstand, den wir unter den Vorstellungen der Materie und körperlicher Dinge verstehen [d. h: das empirische Ding an sich]; denn diese sind Erscheinungen ... Der transscendentale Gegenstand ist, sowohl in Ansehung der inweren als äusseren Anschauung, gleich unbekannt"..2) Dieses transscendentale Objekt, das Kant ausdrücklich mit dem Begriffe des Dinges an sich identifiziert, lässt sich nun, wie er sagt, dogmatisch auf zweifache Weise auffassen. Erweitert man auf seiten des Subjektiven den Begriff der Erscheinung über dessen Grenze hinaus, und macht man das Psychische zum alles Begründenden, so hat man den Spiritualismus, erweitert man auf dieselbe Weise das Materielle, so erhält man den Materialismus. Für Kant ist „das transscendentale Objekt, welches den äusseren Erscheinungen, imgleichen das, was der innern Anschauung zum Grunde liegt, weder Materie noch ein denkend Wesen an sich selbst, sondern ein uns unbekannter Grund der Erscheinungen, die den empirischen Begriff von der ersten [d. $\mathrm{h}$ : der materiellen] sowohl als zweiten [d. h: der psychischen] Art an die Hand geben." ${ }^{3}$ ) Das Resultat wird dieses: Kant sondert zwischen dem empirischen und dem transscendentalen Ding an sich, das empirische ist die Ursache des Objektiven in der Welt der Erscheinungen, das transscendentale ist aber wiederum die Ursache sowohl dieses Objektiven

1) In einer sehr interessanten Abhandlung: „Zu Kants Widerlegung des Idealismus" (Strassburger Abhandlungen zur Philosophie 1884, S. 112 -164) hat Vaihinger Kants Stellung zum Idealismus kritisiert. Ich verweise hier auf meine untenstehende Antikritik.

2) Kr. d. r. V. S. 315 .

3) S. 320, vgl. 328-330. 
$(\mathrm{Ph}-0)$ als des Subjektiven (Ph-S), obgleich es an und für sich uns gan\% unbekannt ist und sich nicht in Ähnlichkeit mit dem Objektiven oder dem Subjektiven bestimmen lässt (0). Die Verwechselung ist hier klar: der Begriff des I)inges an sich ist hier einerseits unbekannt und ausserhalb der Welt der Erscheinungen als transscendentales Ding an sich, weun er hier auch nicht als problematisch aufgestellt wird, anderseits wird er in Analogie mit dem empirischen Ding an sich als kausal wirkend aufgefasst, obschon er sich von letzterem wieder dadurch unterscheidet, dass er die Ursache sowohl des Stoffes als der Form, sowohl des Materiellen als des Psychischen ist. ${ }^{1}$ ) Es ist aber klar, dass ein Schliessen auf dieses Ding an sich durchaus unberechtigt ist; aus den „empirischen Begriffen" des Objektiven und des Subjektiven in der Welt der Erscheinungen kann man nicht zu demselben gelangen, ebensowenig wie man aus den Attributen zu Spinozas Substanz zu gelangen vermag. Ferner ist es klar, wie dadurch, dass sowohl das objektive Substrat (Ph-O) als das Ding an sich (0) als unsere Empfindungen bewirkend gesetzt wird, selbst wenn letzteres auch das Subjektive bewirkt und weiter nach aussen wirkt, weiterer Verwechselung und gefährlichen Konsequenzen der Weg gebahnt wird, indem Kant hier thatsächlich die Grenze der Erkenntnis überschritten hat.

Am klarsten und schärfsten kommt die Verwechselung in dem Abschnitte "Amphibolie der Reflexionsbegriffe"2) zum Vorschein. Hier kämpfen unter dem Worte Ding an sich die Bestimmungen des transscendentalen und die des empirischen Dinges an sich im entschiedensten Gegensatze miteinander. Dieser Gegensatz wird um so schärfer, weil das transscendentale Ding an sich hier klarer und bestimmter entwickelt wird als sonst irgendwo in der Kritik der reinen Vernunft. Es wird am zweckmässigsten sein, hier von dem transscendentalen Dinge an sich auszugehen, dessen Bestimmungen und dessen Verhalten zu den Kategorien genau zu prïfen, und endlich zu zeigen, dass wir hiermit den Weg innerhalb des Begriffes des Dinges an sich vom transscendentalen bis zum empirischen Ding an sich zuriickgelegt haben.

1) S. $306 ; 404$.

2) S. $256-260$. 
Kant giebt folgende Bestimmungen des Dinges an sich: „Verstehen wir darunter nur Gegenstände einer nichtsinnlichen Anschauung, von denen unsere Kategorien zwar freilich nicht gelten, und von denen wir also gar keine Erkenntnis (weder Anschauung noch Begriff) jemals haben können, so müssen Noumena in dieser bloss negativen Bedeutung allerdings zugelassen werden: da sie denn nichts anders sagen, als: dass unsere Art der Anschauung nicht auf alle Dinge, sondern bloss auf Gegenstände unserer Sinne geht, folglich ihre objektive Gültigkeit begrenzt ist, und mithin für irgend eine andere Art Anschauung, und also auch für Dinge als Objekte derselben, Platz übrig bleibt. Aber alsdann ist der Begriff eines Noumenon problematisch, d. i. die Vorstellung eines Dinges, von dem wir weder sagen können, dass es möglich, noch dass es unmöglich sei, indem wir gar keine Art der Anschauung, als unsere sinnliche kennen, und keine Art der Begriffe, als die Kategorien, keine von beiden aber einem aussersinnlichen Gegenstande angemessen ist. Wir können daher das Feld der Gegenstände unseres Denkens über die Bedingungen unserer Sinnlichkeit darum noch nicht positiv erweitern und ausser den Erscheinungen noch Gegenstände des reinen Denkens, d. i. Noumena annehmen, weil jene keine anzugebende positive Bedeutung haben ... dieses [das Noumenon] bedeutet eben den problematischen Begriff von einem Gegenstande für eine ganz andere Anschauung und einen ganz anderen Verstand, als der unsrige, der mithin selbst ein Problem ist." $\left.{ }^{1}\right)$ Hier haben wir das transscendentale Ding an sich in äusserst klaren Ausdrücken. Dasselbe ist der Grenzbegriff nicht nur der Sinnlichkeit, sondern, da reine Vernunfterkenntnis der Dinge nicht möglich ist, auch der der menschlichen Erkenntnis überhaupt. Es sagt also nur: Ob sich ausser dem, was den Formen menschlicher Erkenntnis gemäss erkennbar ist, noch mehr findet, das wissen wir nicht, weil die menschliche Erkenntnis heisst: Erkenntnis unter diesen Formen, und es deswegen durchaus unmöglich ist, etwas darüber zu wissen, inwiefern noch etwas ausserhalb derselben existieren kann. Anderseits würde es aber dogmatisch sein, dies zu bestreiten, eben weil wir nichts wissen, und weil es keinen zwingenden Grund giebt, weshalb wir glauben sollten, die uns bekannte Erkenntnis sei die einzige, die jetzt oder vielleicht künftig einmal zu finden wäre. Wo die menschliche Erkenntnis

1) S. $256-257$; vgl. $235 ; 57$. 
ihrer eigenen Natur zufolge endet, fängt für uns das Ding an sich an, das will aber nur heissen, dass dort jedes Forschen und Wissen aufhört. Das transscendentale Ding an sich ist nur der äusserste und letzte Skeptizismus, ist unwiderleglich, ausser seiner Formulierung aber alles Interesses bar (die geschichtlich-polemische Bedeutung ausgenommen), sagt nur: wir haben kein Recht, dogmatisch zu behaupten, unsere Formen der Erkenntnis seien die einzig möglichen. Dasselbe ist der letzte Zweifel; geschähe das Unmögliche, dass die Erkenntnis überall in der Welt der Erscheinungen von jeglicher Skepsis gerettet wäre, so würde dieser Zweifel doch ewig als der letzte, freilich auch als der bedeutungsloseste dastehen: Er drückt die Negation der Erkenntnis aus, oder ist vielmehr der ewige Problematismus der Erkenntnis, der eigentlich nichts Wirkliches ist und nur die Warnung giebt, als Problem dahingestellt bleiben $\mathrm{zu}$ lassen, was der Natur unserer Erkenntnis zufolge auf ewige Zeit problematisch bleiben muss.

Wir untersuchen nun dieses transscendentale Ding an sich im Verhalten zu den Kategorien, mit welchen Kant es in Beziehung bringt.

Zuerst haben wir den Begriff der Möglichkeit. Kant sagt, wie folgt: $" .$. und so ist der Gegenstand eines Begriffs, dem gar keine anzugebende Anschauung korrespondiert, = Nichts, d.i. ein Begriff ohne Gegenstand, wie die Noumena, die nicht unter die Möglichkeiten' gezählt werden können, obgleich auch darum nicht für unmöglich ausgegeben werden müssen. ${ }^{11}$ ) Das Ding an sich ist ein "Gedankending“, das nicht unter die Möglichkeiten gezählt werden darf, während das „Unding“" der Möglichkeit entgegengesetzt wird, so dass der Begriff sich selbst aufhebt. ${ }^{2}$ ) Nach - Kants Sprachgebrauch ist das Ding an sich deswegen eben nur problematisch, ${ }^{3}$ ) für uns ist dies in der That gleichbedeutend damit, dass es nicht wie bei Kant zwischen Möglichkeit und Unmöglichkeit schwebt, sondern dass es möglich ist und weiter nichts. Wir haben hier den einzigen Ort, wo es in der Philosophie gestattet ist, von einer blossen Möglichkeit zu reden. Das transscendentale Ding an sich enthält also nur das rein Skeptische, dass wir nicht sagen können, unsere Eikenntnisformen seien die einzig möglichen; es sind andere Erkenntnisformen, es sind Gegen-

1) S. 259.

2) S. 260 .

3) S. 257. 
stände ausserhalb der Erkenntnis möglich. Gerade die Möglichkeit gilt nicht von der Welt der Erscheinungen, wo alles entweder notwendig oder unmöglich ist. Aber eben weil wir hier an der letzten, absoluten Grenze der Erkenntnis stehen, ist es zulässig, von einer Möglichkeit (nicht in populärem, sondern in streng erkenntnistheoretischem Sinne) zu reden; es kann möglich sein, dass es ausserhalb der Welt der Erscheinungen (nicht ausserhalb derjenigen, welche wir thatsächlich erkennen, sondern ausserhalb derjenigen, welche wir der Natur unserer Erkenntnis zufolge zu erkennen vermögen) noch mehr giebt, es kann aber auch möglich sein, dass es nicht mehr giebt; wir dürfen hier von einer Möglichkeit sprechen, weil wir a priori wissen, dass es uns an allen Nitteln gebricht, um über die Möglichkeit hinaus zu einer Bejahung oder Verneinung zu gelangen. Der konsequenteste Skeptiker würde vielleicht die Meinung verfechten, es sei uns nicht einmal gestattet, letzteres zu behaupten, da wir nicht wüssten, ob die Natur der Erkenntnis konstant sei, dies müssen wir aber dahingestellt bleiben lassen, indem wir mit Kant von dieser Konstanz ausgehen. Dann wird das Resultat aber auch das hier angeführte; das Ding an sich ist also nur problematisch, und es möchte sehr sonderbar scheinen, sollte sich hiernach noch ein einziges Wort mehr darüber sagen lassen. Dies thut Kant aber, und somit tritt die Verwechselung ein.

Das Ding an sich fällt nämlich unter den Begriff der Notwendigkeit. Man kann von der logischen und von der kausalen Notwendigkeit reden; zur letzteren werden wir uns kehren. wenn wir schliesslich das Ding an sich in seinem Verhalten zum Kausalitätsbegriffe betrachten. Die Frage ist hier also die: wie ist das Verhältnis zwischen dem Ding an sich und der logischen Notwendigkeit? Aus dem oben Entwickelten geht hervor, dass es sich als notwendig verantworten lässt, die Möglichkeit von etwas ausserhalb unserer Erkenntnis zu denken, d. h. eben die Möglichkeit kaun als logisch notwendig dastehen. Diese logische Notwendigkeit des Begriffes hat Kant in der That auch geäussert, wenn auch nicht ganz klar: „Ferner ist dieser Begriff notwendig, um die sinnliche Anschauung nicht bis über die Dinge an sich selbst auszudehnen, und also, um die objektive Gültigkeit der sinnlichen Erkenntnis einzuschränken. (denn das Übrige, worauf jene nicht reicht, heissen eben darum Noumena, damit man dadurch anzeige, jene Erkenntnisse können ihr Gebiet nicht über alles, was 
der Verstand denkt, erstrecken)." ") Das Ding an sich ist selber problematisch, scin Begriff aber notwendig. Es scheint mir deutlicher zul werden, wenn man die Sache folgendermassen anfasst: Jede Definition ist eine Abgrenzung, wodurch ein bestimmter Begriff in cinen gewissen Gegensatz zu allem anderen gebracht wird; Abgrenzung bedeutet in der formellen Logik eine Spaltung in den Begriff und die Negation des Begriffes. Was man „das dialektische Prinzip“ der formellen Logik nennen könnte, sagt dann: Jeder Begriff setzt seine eigene Negation. Es ist klar, dass wenn der Begriff A gegeben ist, dieser gerade dadurch als Begriff gegeben wird, dass er als etwas anderes als Non-A gesetzt ist; durch die Aufstellung des Begriffes zerfällt die ganze Welt in zwei Teile, in A und Non-A. In der Logik ist der Gegensatz des Schwarz nicht das Weiss, sondern das Nicht-Schwarz, und hierzu gehören nicht nur das Weiss und alle anderen Farben, sondern alles andere überhaupt. Wird A gesetzt, so folgt mit logischer Notwendigkeit, dass auch Non-A gesetzt ist; ein Begriff ohne Möglichkeit seiner Negation müsste in absolutem Sinne allumfassend sein. Es wird uns nie verbürgt werden, dass wir wirklich einen solchen Begriff hätten, und eben dieser Mangel an Bürgschaft ist Kants transscendentales Ding an sich. Mit dem Begriff der Erscheinung, der also alles bezeichnet, was wir direkt oder indirekt aufzufassen vermögen, ist in demselben $\mathrm{Nu}$ rein logisch der Begriff der Nicht-E'rscheinung gegeben, da wir aber den Begriff der Erscheinung so umfassend definiert haben, wie ein Begriff sich überhaupt nehmen lässt, können wir weiter nichts sagen, als dass der Begriff der Nicht-Erscheinung in realitate problematisch ist. Wir werden aber nicht die Wirklichkeit der Nicht-Erscheinung bestreiten können, weil uns nie verbürgt ist, dass „Erscheinung“ alles umfasst, eben weil wir an der Grenze der Erkenntnis stehen. Das transscendentale Ding an sich ist mithin, um es kurz zu sagen, nur dieser Mangel an Bürgschaft. Diese logische Notwendigkeit scheint mir völlig verantwortlich zu sein; Kant hat aber eine andere, die, wenn ihr überhaupt Sinn beizulegen ist, in der That real wird. In der ersten Ausgabe der Kritik der reinen Vernunft sagt Kant: „Es folgt auch natürlicher.Weise aus dem Begriffe einer Erscheinung überhaupt: dass ihr etwas entsprechen müsse, was an sich nicht Erscheinung ist, weil Erscheining nichts

1) S. 235 . 
für sich selbst und ausser unserer Vorstellungsart sein kann, mithin, wo nicht ein beständiger Zirkel herauskommen soll, das Wort Erscheinung schon eine Beziehung auf etwas anzeigt, dessen unmittelbare Vorstellung zwar sinnlich ist, was aber an sich selbst, auch ohne diese Beschaffenheit unserer Sinnlichkeit (worauf sich die Form unserer Anschaunng gründet) etwas, d. i. ein von der Sinnlichkeit unabhängiger Gegenstand sein muss." 1) Dieses Argument wird in der Vorrede zur zweiten Ausgabe wiederholt: „Gleichwohl wird, welches wohl gemerkt werden muss, doch dabei immer vorbehalten, dass wir eben dieselben Gegenstände auch als Dinge an sich selbst, wenn gleich nicht erkennen, doch wenigsteus müssen denken können. Denn sonst würde der ungereimte Satz daraus folgen, dass Erscheinung ohne etwas wäre, was da erscheint.“") Es könnte scheinen, als wäre hier von der obengenannten logischen Notwendigkeit die Rede, und Kant erörtert denn auch in einer Note, dass "ein Ding an sich denken“ keinen realen, sondern nur logischen Sinn habe. Zum ersteren werde mehr erfordert, dies könne aber in der praktischen Philosophie liegen. Das hilft in der That aber nichts, denn im Beweise („Sonst würde" u. s. w.) liegt, eben in der theoretischen Philosophie, das Ding an sich als positiver Begriff. Die logische Notwendigkeit enthielt nur die Möglichkeit eines realen Dinges an sich, denn das Ding an sich war ja gerade problematisch. Hieraus folgt nun wieder der "ungereimte Satz", dass „Erscheinung:" sich mit genau demselben Recht und derselben Richtigkeit „ohne etwas, was da erscheint" als mit etwas denken lässt. Kant hat sich hier zum zweitenmal durch das leere Wort bestricken lassen. Es geht ähnlicherweise wie mit dem Worte Ding an sich. In der Dissertation hatte es guten Sinu, von "Erscheinung" zu sprechen, da hier "etwas, was da erscheint," positiv gegeben war. Der Begriff des Phänomens oder der Erscheinung wurde indes erweitert, und der Umfang, den diese Erweiterung erhielt, hätte Kant zur Revision des Wortes bewegen sollen. Dies geschah aber nicht, Kant fand sich hierzu nicht veranlasst, weil der Begriff des Dinges an sich unklar war, da die ethischen und monadologischen Bestimmungen fortwährend im Hintergrunde schwebten. Entweder hätte Kant die Phänomene „alles Seiende“ oder „alles Wirkliche“ statt „Erscheinungen“ nennen sollen, oder auch hätte er den Begriff der

1) S. 233.

2) S. 23 ; vgl. S. 124 . 
Erscheinung so begrenzen müssen, dass derselbe das Resultat von $\mathrm{Ph}-\mathrm{O}$ und Ph-S geworden wäre, - im Gegensatz zum Begriffe des Phänomens als alle 3 umfassend - das man nach den Bestimmungen, die Kant thatsächlich hat, als „Erscheinung der Erscheínungen" hat bezeichnen müssen. Wegen der "Idola fori“ blieb das Ding an sich als positiver Begriff stehen, obschon es problematisch gemacht wurde; wegen der "Idola fori“ beweist das Korrelat „Erscheinung“, dass das Ding an sich notwendig und existierend ist, obgleich ersteres seinen Bestimmungen gemäss das Einzige ist, dem wir Notwendigkeit und Existenz beilegen können.1)

1) Drobisch ("Kants Dinge an sich und sein Erfahrungsbegriff". 1885. S. 14 u. f.) hat es versucht, Kant an diesem Punkte vor dem Jacobischen Einwurfe zu schützen. Das Ding an sich erkennen, sagt Kant, könnten wir nicht, wohl aber uns dasselbe denken, denn ich könne denken, was ich wolle, dies dürfe nur nicht sich selbst widersprechend sein. Dies ist richtig, hieraus zieht Drobisch aber die Konsequenz, im vorliegenden Falle sei es notwendig, sich die Dinge an sich als die Ursachen unserer Empfindungen zu denken. Aber erstens können wir uns das Ding an sich (0) nur als problematisch denken, zweitens ist das Ding an sich als real (was Drobisch dadurch ausdrückt: „da es ja ungereimt wäre, Erscheinungen zu denken ohne etwas, was da erscheint") nicht notwendig, sondern nur möglich, und endlich folgt die Kausalität (die Ursache unserer Empfindungen) nicht aus der Existenz. Das Drobisch'ṣche Ding an sich lässt sich aber nicht einmal denken, denn der Begriff wird bei ihm durchaus sich selbst widersprechend. Es heisst: „Sie werden also notwendigerweise als die Ursachen der Empfindungen gedacht," und dagegen: „Aber dieses Denken ist kein Erkennen, dass sie wirklich existieren ... Gleichwohl ist der Verstand vollkommen berechtigt, die Dinge sich als Ursachen der Erscheinungen zu denken, aber er darf sich nicht anmassen, dieses Denken für eine Erkenntnis auszugeben, dass die Dinge wirklich die Ursachen der Empfindungen sind“. Diese Sätze verhalten sich zu einander wie A zu Non-A. Das Ding an sich wird notwendigerweise als kausal wirkend gedacht, aber dennoch lässt die Kategorie der Kausalität sich nicht auf dasselbe anwenden, und dennoch soll man sich hüten, das Ding an sich für die wirkliche Ursache der Empfindungen zu halten. Hier wie bei Kant bestrickt das Wort „Erscheinung“, der Selbstwiderspruch stammt aber namentlich daher, dass Drobisch völlig das transscendentale mit dem empirischen Ding an sich verwechselt und obendrein, um sich aus der Verlegenheit zu retten, keinen Unterschied zwischen der logischen und der kausalen Notwendigkeit macht.

Auf dieselbe Weise wird die Sache von Rikizo-Nakashima, einem Japaner, genommen („Kant's Doctrine of the Thing-in-itself“. 1889), ohne dass hier etwas Neues zum Vorschein käme. Ich verweise hier ebenfalls auf Lasswitz („Die Lehre Kants von der Idealität des Raumes und der Zeit." 1883). 
Scheinbar ist die Notwendigkeit eine logische („Erscheinung - etwas, was da erscheint"), in der That bezeichnet der Schluss aber - wenn er für anderes als leeres Wortspiel genommen werden soll, - dass etwas Reales dahinter liegen muss. Denn die Erscheinung ist ein Reales, und das Einzige, das mit logischer Notwendigkeit hinzuzudenken ist, wird die Negation des Realen oder die Nicht-Erscheinung; indem Kant nun den Schluss auf "etwas, was da erscheint" zieht, wird diesem etwas Reales beigelegt, das Ding an sich ist nicht mehr problematisch, es ist wirklich.

Somit fällt es auch unter den Begriff des Daseins. Dies kann aber nicht von dem transscendentalen Ding an sich gelten, dem wir ein mögliches Dasein nicht abstreiten könuen; so wie wir aber das Wort "Möglichkeit" auffassten, bedeutet Dasein eigentlich das Entgegengesetzte, indem alles Dasein bedeutet: das Sein für ein Subjekt. Nur die Erscheinungen können ein Dasein haben; indem Kant dem problematischen Ding an sich Dasein beilegt, hat das empirische Ding an sich sich in den Begriff hineingedrängt. 1)

Am klarsten tritt die Grundverwechselung mit Kants Ding an sich zum Vorschein, wo dieses mit der Kausalität in Beziehung gebracht wird. Dies sahen wir bereits im 4. Paralogismus, am entschiedensten tritt es aber vielleicht in der Amphibolie der Reflexionsbegriffe hervor. Unmittelbar nach der bestimmten Entwickelung des Dinges an sich als unerkennbar und problematisch sagt Kant: „Demnach begrenzt der Verstand die Sinnlichkeit, ohne darum sein eigenes Feld zu erweitern, und, indem er jene warnet, dass sie sich nicht anmasse, auf Dinge an sich selbst zu gehen, sondern lediglich auf Erscheinungen, so denkt er sich einen Gegenstand an sich selbst, aber nur als transscendentales Objekt, das die Ursache der Erscheinung (mithin selbst nicht Erscheinung) ist und weder als Grösse, noch als Realität, noch als Substanz u. s. w. gedacht werden kann (weil diese Begriffe immer sinnliche Formen erfordern, in denen sie einen Gegenstand bestimmen)“.2) Wir

1) Eine vorzügliche Kritik der letzten Punkte gab E. L. Fischer („Die Grundfragen der Erkenntnistheorie“. 1887. S. 2:8--240).

2) Kr.d.r. V. 257-258. Da hier die Ursache der "Erscheinung" und nicht die Ursache „der konkreten Empfindung" steht, ist der Deutlichkeit wegen folgendes $\mathrm{zu}$ bemerken. Kant hält die Begriffe "Materie" und „Ding an sich" auseinander, insofern die Materic als solche niemals Ding 
stehen hier an dem bestimmenden Unterschcidungszeichen zwischen dem transscendentalen und dem empirischen Ding an sich, weil wir gerade hier in der Wissenschaft das empirische gebrauchen sollen, und es ist klar, dass dieses, weil es in der Kausalerklärung zur Anwendung kommen soll, zugleich notwendig und existierend werden muss; während dis transscendentale Ding an sich als das problematische, welches uns verwehrt, über die Grenze der Erkenntnis hinaus zu gehen und etwas darüber auszusagen, was jenseits liegt oder ob dort überhaupt etwas liegt, selbstverständlich nicht unter die Kategorie der Kausalität herangezogen werden kann. Den letzten, unlösbaren Zweifel der Erkenntnis als realen Faktor in die Kausalreihe einzusetzen, wäre vernunftgemäss durchaus sinnlos, selbst wenn er als letztes Glied, als letzte, an sich selbst unbekannte, wirkende Kraft gesetzt würde. Ohne Notwendigkeit und Dasein bedeutet der Begriff der Kausalität nichts, und wir haben hier faktisch eine Erkenntnis, selbst wenn man sagen wollte, diese sei sehr gering, da wir unter diesen Kategorien nur Erscheinungen haben und wir unter Erscheinungen das Erkennbare verstehen, ohne Rücksicht auf den Grad der Erkenntnis, ohne Rücksicht darauf, ob wir es mittelbar oder unmittelbar erkennen.

An diesem entscheidenden Punkte musste der Widerspruch bei Kant jedem, 'der die Kritik der reinen Vernunft mit einigem Nachdenken las, deutlich zum Vorschein kommen, und hier griff die Kritik denn auch sogleich an. Jacobi hat die Ehre, zuerst Kants unbeholfenen Selbstwiderspruch auf scharfe und klare Weise nachgewiesen zu haben. Nach einer Darstellung verschiedener Stellen von Kant sagt Jacobi: „Kant verlässt ganz den Geist seines Systems, wenn er von den Gegenständen sagt, dass sie Eindrücke auf die Sinne machen, dadurch Empfindungen erregen und auf diese Weise Vorstellungen zuwegebringen: denn nach

an sich benannt wird, und Ding an sich, wo es positiv bestimmt wird, meines Wissens niemals als direkte Ursache unserer Empfindungen, sondern als eine unbekannte Substanz hinter den Erscheinungen auftritt, welche letztere verursacht. Wenn das Ding an sich aber ïberhaupt in die Kausalreihe gebracht wurde, so bezeichnet das nur einen graduellen Unterschied. Dächten wir uns alles in der Aussenwelt auf den Begriff der Energie reduziert, so würden wir dernoch unzählige verschiedene Ursachen der einzelnen konkreten Empfindungen haben. F..A. Langes Entwickelung ist deshalb gewissermassen konsequent, wenn sie geschichtlich auch unrichtig ist. 
dem Kantischen Lehrbegriff kann der empirische Gegenstand, der immer nur Erscheinung ist, nicht ausser uns, und noch etwas anders als cine Vorstellung sein: von dem transscendentalen Gegenstande aber wissen wir nach diesem Lehrbegriffe nicht das Geringste; und es ist auch nie von ihm die Rede, wenn Gegenstände in Betrachtung kommen; sein Begriff ist höchstens ein problematischer Begriff." ${ }^{1}$ ) Diese Stelle in Jacobis 1787 erschienener Kritik ist klassisch und bezeichnet den grossen Wendepunkt in der Geschichte des Begriffes des Dinges an sich. 1792 erhob G. E. Schulze im "Änesidemus" denselben Einwurf, 2) zwar nicht so klar und entschieden und besonders gegen Reinhold gerichtet, und 1796 schloss J. S. Beck sich von einem idealistischen Gesichtspunkte aus an $;^{3}$ ) endlich trat 1797 J. G. Fichte hinzu. ${ }^{4}$ ) Interessanter als der blosse Nachweis des Widerspruches bei Kant sind indes die Anläufe zur Bestinmmung der beiden Begriffe, die den Widerspruch erzeugten, indem Kant sie wegen der Bezeichnung durch ein und dasselbe Wort miteinander verwechselte. Auch an diesem Punkte gebührt vorerst Jacobi die Ehre, indem er, wie oben citiert, zwischen dem empirischen Objekt, welches Erscheinung ist, und dem transscendentalen Gegenstand, welcher ausserhalb der Welt der Erscheinungen liegt, und von welchem wir deshalb nichts Positives aussagen können, entschiedene Sonderung unternimmt. ${ }^{5}$ )

S. 301 u. f.)

1) Idealismus und Realismus. 1787. S. 220 (Werke 1815. II.

2) Änesidemus. 1792. S. 295-311, vgl. 263 u. f.

3) Grundriss der kritischen Philosophie. 1796.

4) Zweite Einleitung in die Wissenschaftslehre 1797 (Werke I. S. 481 u. f.).

5) Weil diese Distinktion bei Kant so unklar ist, weil hier die Grundverwechselung stattfindet, ist es auch bei Kants Kritikern schwierig, die Begriffe zu bestimmen. Lichtenberg unterscheidet zwischen „praeter nos" und "extra nos" (Vermischte Schriften 1801. II. S. 66-70). Ich glaube nicht, dass Drobisch ("Kants Dinge an sich und sein Erfahrungsbegriff“. 1885. S. 3) berechtigt ist, Lichtenbergs „Dinge praeter nos" ohne weiteres gleich Kants Dingen an sich zu setzen. Lichtenberg sagt: „Weil diese Veränderungen nicht von uns abhängen, so schieben wir sie andern Dingen zu, die ausser uns sind, und sagen, es giebt Dinge ausser uns. Man sollte sagen praeter nos, aber dem praeter substituieren wir die Präposition extra, die etwas ganz anderes ist; das ist, wir denken uns diese Dinge im Raume ausserhalb unser." Es scheint mir aus diesem und aus der weiteren Entwickelung hervorzugehen, dass die „Dinge praeter nos" Kants Stoffe (dem empirischen Ding an sich) entsprechen. 'Es wird nun die 
Eigentïmlicher wird diese Distinktion von Salom on Maim on ausgestaltet. Sehen wir erst, wie er das empirische Ding an sich auffasst. Die Erkenntnis des Dinges an sich, sagt er, ist nichts anderes als die völlige Erkenntnis der Erscheinungen. „Die Metaphysik ist also nicht eine IVissenschaft von etwas ausser den Erscheinungen, sondern bloss von den Grenzen der Erscheiuungen, oder von den letzten Gliedern ihrer Reihen." 1) Diese Äusserungen sind sehr klar. Wäre es denkbar, dass wir die völlige Erkenntnis der Dinge hätten, so wäre auch das empirische Ding an sich erkannt, dies brauchte darum aber nicht auch mit dem transscendentalen, ausserhalb der Welt der Erscheinungen liegenden, der Fall zu sein. Man sieht, dass Maimons Begriffe „die völlige Erkenntnis der Erscheinungen" und "die letzten Glieder der. Reihe" dasselbe aussagen; in der Welt der Erscheinungen können wir das Wort "Ding an sich" erst dann mit Recht anwenden, wenn wir dem Letzten, Abschliessenden und Vollständigen gegenüberstehen. Naimon meint, dies könnten wir in der That nie von uns behaupten, und deswegen werde das Ding an sich (als empirisches also) keine

Frage, mit welchem Recht sich sagen lässt, dass „praeter" zugleich „extra“ sei. Anderseits scheint Lichtenberg die Grundverwechselung noch deutlicher als Kant zu haben, indem er das Ding praeter nos das "Ding an sich" benennt (1. c. S. 72), was Kant nie gethan haben würde, wenn er auch die Bestimmungen verwechselt hätte. Bei Lichtenberg rührt die Verwechselung gewiss vor allen Dingen von seinem eignen idealistischen Gesichtspunkte her, dem zufolge das empirische Ding an sich ebenso illusorisch werden sollte wie Kants Ding an sich als die allen Dingen zu Grunde liegende unbekannte Substanz, ferner daher, dass er Kants Bestimmungen des transscendentalen Dinges an sich nicht richtig aufgefasst zu haben scheint.

Dagegen finden wir die Distinktion klar bei Schopenhauer ("Welt als Wille und Vorstellung." I. ed. Grisebach. S. 566-567): „Demnach unterscheidet Kant eigentlich dreierlei: 1. die Vorstellung; 2. den Gegenstand der Vorstellung; 3. das Ding an sich. Erstere ist Sache der Sinnlichkeit, welche bei ihm, neben der Empfindung, auch die reinen Anschauungsformen Raum und Zeit begreift. Das Zweite ist Sache des Verstandes, der es durch seine zwölf Kategorie hinzudenkt. Das Dritte liegt jenseits aller Erkennbarkeit." Von seiner idealistischen Metaphysik aus verwirft Schopenhauer gänzlich No. 2 (das empirische Ding an sich); in No. 3 geraten aber thatsächlich auch die Bestimmungen aus No. 2 hinein. In Wirklichkeit hat Schopenhauers Metaphysik erkenntnistheoretisch Kants Grundverwechselung zur Grundlage (vgl. Vaihinger: Strassb. Abh. S. 148, die Note).

1) Philosophisches Wörterbuch (1791): I. S. 176-177. 
bestimmte, sondern nur annähernd bestimmte Grösse. Wir könnten unsere Analyse immer weiter fortsetzen, wir könnten z. B. in betreff der Materie alles auf den Begriff der Energie reduzieren, hierdurch werde das Problem der Materie dennoch nicht erschöpft und die völlige Erkenntnis der Welt der Erscheinungen nicht erzielt. Der Natur unserer Erkenntnis zufolge, die stets nur Beziehungen aufzufassen vermöge und niemals im stande sei, zu verbürgen, dass wir alles aufgefasst hätten, werde das Ding an sich, obschon in der Welt der Erscheinungen liegend, sich nie völlig bestimmen lassen und sei deshalb mit $\sqrt{2}$ zu vergleichen, welche Grösse sich durch jede hinzukommende Dezimale genauer, aber nie mit völliger Genauigkeit bestimmen lasse. Hieraus folge nun wieder, dass man das Wort "Ding an sich" eigentlich auch mit Bezug auf das empirische Ding an sich aufgeben sollte, denn das Ding an sich sollte gerade $=$ der völligen Erkenntnis der Dinge sein, und diese sei nie zu erreichen, wie weit wir auch zurückgingen; an einem bestimmten Punkte müssten wir Halt machen, „und wird hier nicht selbst der arme Indianer seine Frage erneuern: und worauf ruht endlich die Schildkröte?"1) - Die Reihe der Ursachen ist unendlich, somit ist die eine Grenze gegeben, und dadurch, dass wir nur Beziehungen auffassen, nie einem Etwas als dem absolut Letzten gegenüberstehen, dass also z. B. der Begriff der Energie schliesslich doch nur ein in der Welt der Erscheinungen wirkendes ausgedehntes Etwas wird, haben wir die Grenze auf eine andere Weise; diese beiden Grenzen liegen im Worte Phänomen, und Maimon. hat durch seine klaren Bestimmungen und sein treffendes Bild den Begriff der Grenze ${ }^{2}$ ) weit deutlicher hervorgehoben als Kant, der sogar die rein negative Grenze positiv machte und durch sein kausal wirkendes Ding an sich schliesslich in der That wieder die Grenze aufhob.

Ausser dem empirischen entwickelt Maimon auch Kants transscendentales Ding an sich. Der Begriff der Idee, der nach Maimon -Vorstellungen bezeichnet, welche sich in einem Objekt nicht völlig darstellen lassen, deren völliger Darstellung man sich aber bis ins unendliche nähern kann, wird in 5 Klassen geteilt, in mathematische Begriffe, Zeit und Raum, die Kategorien, die Differentiale und endlich die irrationalen Grössen. Der Unterschied zwischen demus).

1) Versuch einer neuen Logik. 1794. S. 371 (Briefe an Änesi-

2) Kritische Untersuchungen. 1797. S. 158. 
dem empirischen und dem transscendentalen Ding an sich wird durch den Unterschied zwischen der 4. und der 5. Klasse der Begriffe ausgedrüickt. $\sqrt{2}$ lässt sich nicht völlig bestimmen, ist aber doch ein Grenzbegriff, dem nian sich (mittels unendlicher Reihen) immer mehr zu nühern vermag. Dagegen ist $\sqrt{-a}$, womit Maimon das transscendentale Ding an sich bezeichnet, „ein unmöglicher Begriff, ein absolutes Nichts.“ $\left.{ }^{1}\right)$ Maimon sagt: „Die Algebra gebraucht zwar gleichfalls den Begriff von $\sqrt{-a}$, aber nicht um dadurch ein Objekt zu bestimmen, sondern gerade umgekehrt, um die Unmöglichkeit eines solchen Objekts, dem dieser Begriff zukommt, darzuthun. "2) Und - hier ganz davon abgesehen, ob das Gleichnis an und für sich mathematisch richtig ist - eben dies sollte am transscendentalen Ding an sich hervorgehoben werden, dasselbe soll gerade nur das Negativste von allem sein, soll anzeigen, dass wir nicht von etwas ausserhalb der Erscheinungen reden können, dass wir nicht im stande sind, ausserhalb deren Grenze in irgend einer Richtung das Allergeringste auszusagen.

Mit dem Ausgang des achtzehnten Jahrhunders verstummte allmählich die Diskussion über Kants Begriff des Dinges an sich, und als ein halbes Jahrhundert später der Neu-Kritizismus dieselbe wieder aufnahin, stellte die Sache sich so, dass der Knotenpunkt auf natürliche Weise die Stelle bei Kant wurde, wo die Verwechselung am deutlichsten zum Vorschein gekommen war,

1) Kritische Untersuchungen. S. 153-159.

2) Kritische Untersuchungen. S. 191. Von dieser Entwickelung aus muss gewiss auch folgende Äusserung in Maimons "Lebensgeschichte" (II. S. 43 in der Note) aufgefasst werden: „Die Natur der irrationalen Zahlen z. B. zeigt uns, dass man von einem Dinge, als Objekte an sich, keinen Begriff haben, und dennoch sein Verhältnis zu andern Dingen bestimmen kann." Durch das transscendentale Ding an sich - als regulatives Prinzip - bestimmen wir das Verhältnis zwischen Erscheinung und Nicht-Ersoheinung als eine absolute Grenze: jede Erkenntnis ist subjektiv;, Das Beispiel in der Note scheint ein wenig unpassend gewählt und trägt schwerlich dazu bei, das Verhältnis zwischen dem empirischen und dem transscendentalen Ding an sich aufzuklären; in Maimons letzter Schrift („Kritische Untersuchungen," 1797) ist die Distinktion am schärfsten und klarsten durchgeführt, und die Konsequenzen werden ohne Schwanken gezogen. (Vgl. über Maimon: Erdmann: „Die Entwickelung der deutschen Spekulation seit Kant." 1878. I. S. 520, und Höffding: "Geschichte der neueren Philosophie," II. S. 642.) 
weshalb das Interesse sich denn auch um Jacobis Kritik sammelte. Mit Recht, denn hier lag der entscheidende Punkt; war dieser ins reine gebracht, so konnten vielleicht auch an den anderen Punkten bei Kant die Schwierigkeiten leichter aus dem Wege geräumt werden. Das Unglück bei der ganzen Diskussion, die der NeuKritizismus erregte, lag darin, dass er, wie es seiner ganzen Stellung $\mathrm{zu}$ älteren Richtungen der deutschen Philosophie gemäss zu erwarten war, in seinem Verhältnisse zu Kant selbst weniger kritisch auftrat, so dass die Diskussion über Kants Theorien ein sehr apologetisches Gepräge erhielt, und dass die Kritik wesentlichst nach aussen gegen die Romantik und den Materialismus gerichtet wurde. Jacobis Kritik wurde der Punkt, gegen den sich alle Antikritiken wandten, zugleich übersah man jedoch die Distinktion bei Kant, die Jacobi hervorgehoben und Maimon so klar und entschieden ausgestaltet hatte. Man ging auf Kant zurück, sah aber nicht, dass Maimon die kritische Philosophie in der That eine bedeutende Strecke weiter als Kant gebracht hatte; es wäre deshalb eine Aufgabe für die jüngsten Richtungen des Neu-Kritizismus, Naimon wiederzuentdecken, so wie der Neu-Kritizismus des 19. Jahrhunderts Kant wiederentdeckte. Ohne dass Kants Verdienste hierdurch geschmälert würden, dürften viele Punkte seiner Philosophie in einem anderen Lichte erscheinen. Es lässt sich gewiss auch behaupten, dass der Neu-Kritizismus dem fertigen System (namentlich der mehr realistischen Seite desselben) gar zu grosses, der merkwürdigen geschichtlichen Entwickelung des Systems (und im Zusammenhang hiermit der die verschiedenen Stadien Kants durchziehenden metaphysischen Unterströmung) gar $\mathrm{zu}$ geringes Gewicht beilegte.

Diese Mängel treffen wir recht deutlich bei Friedrich Albert Lange, dem bedeutendsten Vorkämpfer des Neu-Kritizismus an. Mit aller Achtung vor Langes bedeutendem und bahnbrechendem geschichtlichem Werke muss doch gesagt werden, dass er in der vorliegenden Frage nicht verstanden hat, wie Kant das Problem geschichtlich aufgestellt hatte. Wie bemerkt, konzentriert der Neu-Kritizismus den Streit um Tacobis Kritik, also um das Verhalten des Dinges an sich zur Kausalität, und hier wählt auch Lange seinen Ausgangspunkt; er führt - ohne Jacolis Namen zu nennen - den Jacobischen Einwand an, meint aber, es sei nicht so schwierig, diesen $\mathrm{zu}$ widerlegen. ${ }^{1}$ ) Das fällt Lange
1) Geschichte des Materialismus.
3. Aufl. II. S. 48-50, 63, 136. 
denn auch nicht schwer, ganz einfach weil er unter dem Kantischen Begriffe des Dinges an sich nur das empirische Ding an sich versteht. Lange hat in der 'That den Blick auf das Wesentliche gerichtet, denn eben hier liegt das Problen, das transscendentale Ding an sich ist thatsächlich ohne Interesse für die positive Wissenschaft; darum hat Lange in geschichtlicher Beziehung aber doch nicht recht. Das Ding an sich, sagt er, ist ein Grenzbegriff, und dies erhellt er durch folgendes naives Bild: „Der Fisch im Teiche kann nur im Wasser schwimmen, nicht in der Erde; aber er kann doch mit dem Kopf gegen Boden und Wände stossen." Dies passt aber gar nicht, denn der Fisch erkennt, dass Wände und Boden existieren, die Erde ist ilım, wiewohl eine Grenze, doch zugleich eine höchst unangenehme Realität; man beachte aber, dass Kants transscendentales Ding an sich allerdings eine existierende Grenze bezeichnet, dass aber, was für Lange die härteste Realität ist, die. der Fisch antreffen kann, für Kant ein Problem ist und keine Realität, gegen die der Fisch mit dem Kopfe stossen kann. Wie ist der Fisch im stande, die Erde als Wand und Boden, als reale Grenzen zu erkennen, wenn das Wasser für ihn alle Realität ist? Ebenso wie Lange bei dem Begriff der Grenze Kants transscendentale Bestimmungen übersieht, thut er dies auch bei dem Begriffe „problematisch“. Ihm ist nämlich in Konsequenz des Vorangehenden das Ding an sich nicht schon als Existenz problematisch, sondern ein problematisches Etwas, d. h. wir wissen nicht, was die Erscheinungen zu allerletzt sind; . weil wir nur Beziehungen kennen, sind wir nicht im stande, das innerste Wesen der Dinge zu erkennen. Dieser Gebrauch des Wortes „problematisch" stimmt aber durchaus nicht mit dem Kantischen überein. ${ }^{1}$ )

Wenn Lange seine Verteidigung Kants wesentlich auf den Ausdruck "Grenzbegriff" stützt,· so wird es mit den Kantischen Bestimmungen des Begriffes des Dinges an sich vor Augen klar sein, dass der Begriff der Grenze zweideutig ist. Nach der ganzen Weise, wie Lange das Kantische Problem stellt, und nach dem Zusammenhange, in welchem dies geschieht, haben wir hier das empirische Ding an sich vor uns, das eine direkte Fortsetzung der primären Qualitäten Lockes ist. Um unsere Empfindungen zu er-

1) Vgl. Kr. d. r. V., S. 256-260. G. Spicker lieferte hier eine vortreffliche Kritik Langes („Kant, Hume und Berkeley.“ 1875. S. 47 u. f.), auf welche ich verweise. 
klären, werden wir gezwungen, ein Objektives, etwas ausserhalb des Subjektes, anzunehmen. ${ }^{1}$ ) Stellen wir das Gedankenexperiment an, es sei uns gelungen, dieses objektive Substrat auf eine einzige Urkraft zu reduzieren, die überall wirkte, so ist es klar, dass wir hier an einer Grenze stünden. Wir hätten alles auf eine einzige Grundform zurückgeführt, was diese Grundform aber sei, vermöchten wir nicht auszusagen, da wir dem Letzten, Allumfassenden gegenüberstehen würden. Dies würde, obschon sonst unbekannt, doch ein existierendes, kausal wirkendes Etwas sein, oder mit anderen Worten der letzte Begriff, zu dem unsere Analyse uns in der Welt der Erscheinungen führeu könnte. Unter der beständigen Voraussetzung, dass unser Gedankenexperiment gelingen könnte, leuchtet es ein, dass wir bei der Analyse und Reduktion auf verschiedene variable Grenzen stossen würden; jedesmal, wenn sich der Begriff vereinfachte, würde die Grenze weiter hinausgeschoben werden: alles, was wir unter unser Wissen heranzögen, müsste aber schon vorher innerhalb der Welt der Erscheinungen liegen, selbst wenn wir dies erst nachher erführen. Sogar der letzte Begriff, zu dem wir mittels unseres Gedankenexperimentes gelangten, würde eine Grenze bezeichnen, die innerhalb der Welt der Erscheinungen läge, eben weil wir niemals über diese hinaus kommen können. Deshalb bezeichnet das transscendentale Ding an sich auch eine ganz andere Grenze. An der ersteren Grenze müssen wir vor etwas Halt machen, das existierend und kausal wirkend ist, an der anderen Grenze machen wir Halt vor einem Begriffe, der problematisch ist. Hätten wir auch sowohl das Problem der Materie als das der Seele gelöst, so wäre der letzte Zweifel des Bewusstseins damit nicht gehoben, denn ausserhalb der beiden könnte etwas liegen, das in jeder Beziehung sowohl von dem Materiellen als den Psychischen verschieden wäre; selbst wenn Spinozas Problem durch den Begriff der Substanz, gelöst wäre, hätten wir darum doch nicht die unendlich vielen anderen Attribute erkannt. Wären auch alle Dezimalen der $\sqrt{2}$ gefunden, so bliebe $\sqrt{-a}$ doch eine ungelöste Grösse; wäre alles in der IVelt gefunden, so könnte es doch für eine ganz andere Erkennt-

1) Wo man eine Erklärung geben will, kann man dem objektiven Faktor nicht entgehen. Bei Fichte kommt dieser im "transscendentalen Ich" zum Vorschein, und bei Mill liegt 'er in den "possibilities of sensation", die in der That gerade das Objektive bezeichnen, was in der Bestimmung liegt, dass sie bestimmten Gesetzen gemüss aufeinander folgen. 
nis als die unsrige Objekte geben. Denn das empirische Ding an sich setzt, selbst wenn es bis an seine letzte Grenze analysiert ist, doch stets unsere Erkenntnis, d. h. die Anschauungsformen und die Kategorien voraus; das transscendentale Ding an sich fasst aber erst darauf an und sagt: es kann eine ganz andere Art der Erkenntnis geben, die ganz andere Objekte haben kann. Als Grenzbegriff liegt das transscendentale Ding an sich ausserhalb des empirischen, und es liegt in dieser Entwickelung, dass die Entfernung zwischen den beiden Grenzen unendlich weit ist.1)

Das angestellte Gedankenexperiment wird sich aber gewiss nie verwirklichen lassen. In der Wissenschaft hat es indes auch nur sehr geringes Interesse; ob das objektive Substrat sich auf eine einzige Grundform reduzieren lässt oder nicht, ist ziemlich gleichgültig, es kommt darauf an, zu Grössen zu gelangen, mit denen wir wirklich und mit denen wir genau rechnen können. Und wir wissen ja durchaus nicht, ob es überhaupt eine gemeinschaftliche Grundfor'm giebt, vielleicht würde es sich erweisen, wenn wir den Erscheinungen wirklich auf den Grund kämen, und wenn uns überdies verbürgt würde; was noch unmöglicher wäre, dass wir wirklich den Grund erreicht hätten, dass wir vor einer grossen Menge verschiedener Formen Halt machen müssten. Mit Bezug auf das empirische Ding an sich gilt in letzter Instanz Humes Äusserung: „Beweist man von einem Gegenstande alle Eigenschaften, die sich erkennen lassen, sowohl die primären als die sekundären, so ist derselbe gewissermassen vernichtet, und es bleibt nur ein gewisses unbestimmtes und unaussprechliches „Etwas“ als Ursache unserer Empfindungen übrig, ein Begriff, der so mangelhaft ist, dass kein Skeptiker ihn eines Streites wert finden würde.“ 2)

Das Problem des empirischen Dinges an sich wird schwerlich $\mathrm{zu}$ lösen sein, und es ist deswegen auch nicht angemessen, die Grenze, welche das empirische Ding an sich bezeichnet, durch $X$ auszudrücken, denn dieses Symbol leitet den Gedanken leicht auf ein gemeinschaftlich Umfassendes hin. Legt man aber das ganze Ge-

1) Von dem Begriffe der Grenze aus argumentiert auch $\mathrm{H}$. Cohen, wenn er Kants Ding an sich verteidigen will. („Kants Theorie der Erfahrung." 1871. S. 239-253 und "Kants Begründung der Ethik." 1877. S. 18-36); die Beweisführung selbst ist aber so falsch und entfernt sich so weit von Kants eigenen Meinungen und Äusserungen, dass ich glaube, diese Apologie unberücksichtigt lassen zu dürfen.

2) Inquiry concern, human understanding (Selby-Bigge). S. 155. 
wicht darauf, dass durch $\mathrm{X}$ bezeichnet wird, was sich nicht bestimmen lässt, so ist das Symbol statthaft. Dass Lange dies so klar und entschieden gegen den Materialismus verfocht, hat gewiss etwas dazu beigetragen, dass er das transscendentale Ding an sich bei Kant übersah, ebenso wie Kant selbst sich gewiss mittels der Worte "unbekannt" und "Grenze", die also alle beide sowohl auf das empirische als auf das transscendentale Ding an sich anwendbar sind, tiefer in seiner Verwechselung verfing. Während es zulässig sein wird, das Symbol X mit Behutsamkeit vom empirischen Ding an sich zu gebrauchen, ist es dagegen sehr ungeeignet und irreleitend, dasselbe auf das transscendentale anzuwenden. Es sind hier wieder die geschichtlichen Ümstände in Erinnerung zu bringen. Das Ding an sich, das in der Dissertation das Realste von allem war, sollte der Kritik der reinen Vernunft zufolge sogar existentialiter - problematisch sein; unbewusst täuscht Kant aber fortwährend sich selbst, indem der mundus intelligibilis thatsächlich bestehen bleibt und nur die Brücke zu diesem hinüber von der Kritik der reinen Vernunft abgebrochen wird. Auch hier bestrickt das Wort oder das Symbol, wenn Kant das Ding an sich $\mathrm{X}$ nennt, denn bei $\mathrm{X}$ wird etwas hinzugedacht, das, selbst wenn es sich nicht näher bestimmen lässt, so doch existiert, und wirkt. Das transscendentale Ding an sich war aber problematisch, drückte nur die Negation der Erkenntnis aus. $\mathrm{X}$ ist ein irreleitendes Symbol, und das Symbol, das wir vorher, um Kants Gedankengang zu verfolgen, auf das transscendentale Ding an sich anwandten,ist ebenfalls ungeeignet, denn es ist klar, dass $O$ in der That gleich Non-O wird, weil es hier gilt, dass ein Objekt, das kein Objekt für ein Subjekt ist (mithin durch $\mathrm{Ph}-\mathrm{O}$ ausgedrückt) kein Objekt ist. Als klareren Ausdruck des transscendentalen Dinges an sich möchte ich hier, nachdem ich den Begriff nun präzisiert habe, das Symbol Non-E vorschlagen, man möge hierunter nun Non-Erscheinung oder Negation der Erkenntnis verstehen.

In der Welt der Erscheinungen haben wir aber nicht nur die materiellen, sondern auch die psychischen Erscheinungen, und wollten wir eine Reduktion der letzteren unternehmen, so scheinen wir noch schwieriger gestellt $\mathrm{zu}$ sein als den materiellen gegenüber. Wir machen vor gewissen Grundfunktionen Halt, wie wir hinsichtlich des Materiellen vor gewissen verschiedenen Energieformen Halt machen; sollen wir aber mit diesen Grundfunktionen rechnen, so befinden wir uns im höchsten Grade im ungewissen. 
Als Grundform der psychischen Erscheinungen stellte Kant die Synthese auf, und wie später gezeigt werden wird, führte er diese so aus, dass sie als freier Wille, als „homo noumenon“ (S) das Ding an sich der psychischen Erscheinungen (Ph-S) wurde. Es stellt sich dar, dass die Synthese - ist hierunter wirklich ein Begriff zu verstehen, der in der Psychologie Wert besitzt - innerhalb der Welt der Erscheinungen liegen muss, und dass dasselbe von dem „reinen Subjekt" (S) wic auch von dem „reinen Objekt“ (0) gilt: beide sind problematisch, wir können nicht einmal- wissen, ob sie existieren. Bei Nacht sind alle Kühe schwarz, und ausserhalb der Welt der Erscheinungen trifft alles im Symbole Non-E zusammen, weil wir nicht einmal wissen, ob es etwas giebt, das zusammentreffen kann. Eben diese absolute Unerkennbarkeit bedingte, dass Kant nach einer Verwechselung des empirischen und des transscendentalen Dinges an sich an der sonderbaren Auffassung festhalten konnte, das Ding an sich sei die Ursache sowohl des Geistes als der Materie, obschon es doch scheinen möchte, dass das empirische Ding an sich und die Synthese oder der homo noumenon als der freie Ville an und für sich ziemlich voneinander verschieden wären. In der 4. Dimension des transscendentalen Dinges an sich treffen sie sich aber und fallen sie miteinander zusammen.1)

1) Nach Kant könnten wir nun folgendes Schema aufstellen:
A $\begin{aligned} & 0=\text { Non-E Transscendentales Ding an sich } \sqrt{\frac{-a}{6}} \\ & \text { Ph-O der Grundstoff }=x \text { Empirisches Ding an sich } \sqrt{2}\end{aligned}$
A $\mathrm{Ph}-\mathrm{S}>$ die Synthese $=\mathrm{y}$ Empirisches Ich $\sqrt{2}$
$\mathrm{~S}==$ Non-E "homo noumenon" $\sqrt{\div \mathrm{a}}$

Die Grenze A ist absolut, innerhalb der Grenze A, mithin innerhalb der Welt der Erscheinungen haben wir die wirkliche Grenze, die sich senkrecht zu A immer weiter hinausschieben lässt. Diese Grenze ist, wie Höffding sagt, „der philosophische Ort der religiösen und metaphysischen Spekulationen“, wenn diese Spekulationen überhaupt in irgendwelcher Beziehung zum Leben und zur Wissenschaft stehen sollen. Die absolute Grenze A bietet nur sehr wenig Interesse dar, für die Wissenschaft ist es aber von allergrösstem Interesse, ins reine zu bringen, worin die andere, variable Grenze besteht, 'wo sie liegt, wie sie $\mathrm{zu}$ ziehen ist, und welche Konsequenz eben daraus folgt, dass sie gezogen wird. Es leuchtet ein, dass sie für $\mathrm{Ph}-\mathrm{O}$ und $\mathrm{Ph}-\mathrm{S}$ verschieden liegen kann, im einen Gebiete sind wir vielleicht im stande, viel mehr Dezimalen zu finden als im anderen. Die Theologie glaubt nun gerade, alle Dezimalen der $\sqrt{2}$ gefunden und somit,das "Welträtsel" gelöst und die "Weltformel" erforscht zu haben, da- 
Man könnte die Sache auch so betrachten: Kants Ding an sich entstand durch eine Spaltung des Substanzbegriffes der alten Metaphysik, des unbekannten, allen Dingen zu Grunde liegenden „Etwas“. Kant sah nun ganz richtig ein, dass dieses Etwas für uns eigentlich gleich nichts zu setzen ist, wenn wir natürlich auch nicht leugnen dürfen, dass durchaus unbekannte Substanzen für andere Erkenntnisformen als die unsrigen Existenz haben können, und hieraus hat sich das transscendentale Ding an sich entwickelt. Der alte metaphysische Substanzbegriff war die Ursache aller Dinge; wenn wir aber unsere Empfindungen erklären sollten, wurden wir dennoch nicht klüger durch den Hinweis auf dieses unbekannte und unerkennbare „Etwas", das ebensowohl ein Nichts sein konnte. In der Wissenschaft sind wirkliche Faktoren und genaue Bestimmungen erforderlich, und die andere Seite des alten metaphysischen Substanzbegriffes wird dann, was Kant das objektive Substrat, die Materie, die Aussenwelt u. s. w. nennt. Dies nennt Kant nicht das Ding an sich, weil es innerhalb der Velt der Erscheinungen liegt, und - wie wir bei der Erörterung der Dissertation sahen - operiert Kant mit der Welt der Erscheinungen und mit deren Gegensatze, indem die Welt der Erscheinungen deutlich bestimmt ist. Da aber das Ding an sich zur Ursache der Erscheinungen gemacht wird, muss es ganz dasselbe werden wie der alte Substanzbegriff der Metaphysik, der genauer präzisiert wird, indem Kant ihn als das ebenso wie Spinozas Substanz sowohl dem Psychischen als dem Materiellen zu Grunde Liegende setzt. Das Unglïck kommt daher, dass Kant bei weitem nicht klar genug bestimmt hat, was die Materie ist, namentlich

gegen sind die Theologen doch so vernünftig gewesen, sich nicht über Kants transscendentales Ding an sich zu äussern, es sei denn, dass sie sich derselben Verwechselung wie Kant schuldig gemacht oder, wie Kant es ausdrückt ."eine ganz andere Erkenntnis" als die menschliche angenommen hätten. Und selbst dann haben sie, ebensowenig wie sie sich jemals über die psychologische und logische Beschaffenheit dieser "höheren“ Erkenntnis näher ausgelassen haben, uns keinen einigermassen klaren Bescheid von den sehr problematischen „Objekten" dieser Erkenntnis gegeben. Das Religiöse muss trotz aller theologischen Spekulationen innerhalb der Welt der Erscheinungen liegen, wenn es auch ausserhalb der Grenzen liegt, wo unser Wissen vorläufig (und vielleicht ewig) Halt machen muss. Der Gott, der nicht für Menschen wirkt und sich nicht von Menschen erkennen lässt, ist kein Gott. Nur für Theologen kann Gott in der 4. Dimension sein, für

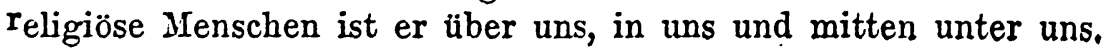


nicht, in welchem Sinne der Materienbegriff ein Grenzbegriff ist, entstammt aber besonders den monadologischen und ethischen Bestimmungen, die iiberall als ein dunkler Untergrund liegell, welcher in aller Stille die Begriffe umschuf und auf sonderbare Weise miteinander vermischte. Sowohl wo Kant den alten Substanzbegriff zum transscendentalen Ding an sich entwickelt, als wo er (z. B. gegen die Idealisten) mit Recht die Realität der Aussenwelt hervorhebt, haben wir die realistischen Entwickelungen seiner Philosophie vor uns. Diesen zur Seite gehen aber - freilich weit schwerer zu verfolgende - Reaktionen, welche die Begriffe vermengen, in Kants Ethik erstaunliche Resultate und in seiner theoretischen Philosophie erstaunliche Widersprüche erzeugen. Wird das transscendentale Ding an sich klar und deutlich definiert und wird das empirische Ding an sich gleich den materiellen Formen gesetzt, mit welchen wir in der Wissenschaft rechnen müssen, so sind beide Begriffe völlig zulässig, der Substanzbegriff dagegen ist ein durchaus unzulässiger Begriff, weil er nichts zu beweisen vermag, und weil er - unbeschadet des Beweises - für die Wissenschaft nutzlos ist. Der Begriff des Dinges an sich, den Lange entwickelt, ist allerdings das empirische Ding an sich, denn er liegt innerhalb der Welt der Erscheinungen, wie oft er auch ein Grenzbegriff genannt werden mag, er ist aber zugleich der alte Substanzbegriff, weil er als Ursache des Materiellen, oder vielmehr als das Materielle in dessen möglichst reduzierter Gestalt, gerade dadurch, dass er die Möglichkeit dieser durchgeführten Reduktion ausdrïckt, eine Einheit des Materiellen postuliert, die keine wissenschaftliche Berechtigung hat. Diese Einheit liegt thatsächlich bei Kant zu Grunde, wenn er auch erklärt, „das Innerliche der Materie" oder das Ding an sich im empirischen Sinne, welches uns als Materie erscheint, "sei eine blosse Grille“, 1) und schliesslich. wird sie zur grossen, sowohl die Materie als den Geist umfassenden Welteinheit erweitert.

Das Bedürfnis der Einheit hat auch in der Geschichte der Philosophie Schaden angerichtet; in der Frage nach dem Verhältnisse zwischen Seele und Körper sollte man meinen, dass wir in einem durchaus entschiedenen und unabwendbaren Dualismus enden müssten, und innerhalb des Materiellen allein wäre es ja leicht möglich, dass die im Laufe der Zeit von

1) Lange: Geschichte des Materialismus. II. S. 50. 
der Wissenschaft unternommene Reduktion nur eine scheinbare wäre, dass wir einen Punkt erreichten, an welchem wir wieder den Rückweg antreten müssten, so dass die Bewegung in der Richtung der Mannigfaltigkeit zurückführte. Weshalb sollten wir in der Wissenschaft nicht mit einer Mannigfaltigkeit enden, da eine durchgeführte Einheit der Natur unserer Erkenntnis zufolge doch nicht möglich ist, wie denn auch alles im Leben vielmehr auf den grossen unabwendbaren Gegensatz zwischen Ideal und Wirklichkeit hinzudeuten scheint. Warum nicht ein kritischer Dualismus statt eines kritischen Monismus? Dies sind schwierige Probleme, die wohl nie eine streng wissenschaftliche Lösung finden werden; von ihrer Lösung oder Unlösbarkeit abgesehen ist es jedoch klar, wie Kant sowohl dadurch, dass er das Ding an sich (wie Lange dieses entwickelt) den kausalwirkenden einheitlichen Grund aller Materie sein lässt, als auch dadurch, dass er demselben eine Erweiterung giebt, die es auch zur prästabilierten Harmonie des Psychischen und des Materiellen, zum Gotte der Okkasionalisten oder zur Substanz Spinozas macht, und dadurch, dass er sowohl Stoff als Formen aus demselben ableitet, das Ding an sich in die Metaphysik hinüber befördert. Selbst wenn es Lange nicht gelungen ist, Kant $\mathrm{zu}$ verteidigen, selbst wenn er diese Verteidigung in geschichtlicher Beziehung durchaus unrichtig aufstellte, und selbst wenn Langes eigne Entwickelung des Verhältnisses zwischen dem Objektiven und dem Subjektiven als irreführend zu betrachten ist, 1 ) hat seine Behandlung, und besonders der Angriff, den er hierin auf den Materialismus richtete, dennoch in mehreren $\mathrm{Be}$ ziehungen Licht uiber das Problem verbreitet.

Den zweiten bedeutenderen Versuch, der vom Neu-Kritizismus angestellt worden ist, um Kant vor Jacobis Einwand zu

1) Vgl. die Entwickelung bei Höffding: Geschichte der neueren Philosophie. II. S. 611 u. f. - Das 4. Stadium lässt sich selbstverständlich verteidigen, in der Wissenschaft müssen wir aber mit objektiven Grössen rechnen - vorläufig jedenfalls, und hier ist gerade das 2. Stadium das richtige und zulässige. Das Ding an sich des 3. Stadiums ist eben die unbekannte Substanz der alten Metaphysik, die Hume keines Polemisierens wert hält, die nach Ostwalds Meinung nichts ist, und die unserer Behauptung nach Schaden stiftet, weil sie auf eine Einheit der materiellen Welt hindeutet, zu deren Annahme kein Grund vorliegt, und die in der positiven Wissenschaft nicht als hilfreiche Hypothese zu verwerten ist. Vgl. Hoffdings Kritik (1. c. S. 612-614). 
schiitzen, treffen wir bei Benno Erdmann,1) Kuno Fischer") und endlich mit grösserer Vorsicht entwickelt bei Fr. Paulsen ${ }^{3}$ ) an. Kurz zusammengefasst geht dieser Versuch darauf aus, zu behaupten, Jacobis Einwurf falle weg, weil Kant, wo er das Ding an sich kausal wirkend sein lasse, nicht an Kausalität im üblichen Sinne des Wortes denke, sondern an die "Freiheitskausalität", wie sie mit einem sonderbaren, sich selbst widersprechenden Worte benannt wird. Die Ethik und das praktische Ding an sich (homo noumenon) werden mithin in die Diskussion hineingezogen. Das Berechtigte dieses Verfahrens liegt erstens darin, dass für Kant ethische Motive während seiner Bestimmungen des Dinges an sich eine grosse Rolle gespielt zu haben scheinen. Wir sahen, dass dies in hohem Grade in den Erdmannschen Fragmenten zum-Vorschein kam. Zweitens darin, dass Kant, nachdem er das Ding an sich als Ursache des Stoffes und das Ding an sich als Ursache der Form zum Ineinanderfliessen gebracht hatte, in der That, da das Ding an sich als Ursache der Form ein ethisches Plus voraus hat (die Synthese als Ding an sich + homo noumenon, als der freie Wille und der soziale Gemeinwille), sehr wohl hätte praktische Bestimmungen in die theoretische Philosophie einführen können, und endlich drittens darin, dass es scheinen könnte, als wäre das die Ursache der Form enthaltende Ding an sich an mehreren.Orten im Verhältnis zu dem die Ursache des Stoffes enthaltenden Dinge an sich als das Fundamentale aufzufassen, weil das alles in der Welt der Erscheinungen Begründende, obschon es häufig als etwas der unbekannten Substanz Spinozas Ähnliches aufgestellt wird, dennoch in Ähnlichkeit mit den Leibnizschen Monaden spiritualistisch aufgefasst $\mathrm{zu}$ sein scheint, was Kant in seinen früheren Stadien ja auch entschieden that, und was er trotz seiner Kritik voll Leibniz eigentlich ebenfalls, obschon ziemlich verborgen, im definitiven System thut. ${ }^{4}$ Die Betrachtung schützt Kant jedoch nicht. Ob Kant sich nicht auf dem ethischen Gebiete, wenn der Streit in dieses hinüber geführt würde, in einer ebenso schwierigen Lage wie auf dem theoretischen be-

1) Kants Kritizismus in der 1. u. 2. Aufl. seiner Kr. d. r. V. (1878).

2) Kritik der Kantischen Philosophie (1883). S. 89-96, vgl. 58-75.

3) Immanuel Kant (1898). S. 153-155.

4) O. Riedel: Die monadologischen Bestimmungen in Kants Lehre vom Ding an sich (1884);, vgl. Höffding: Geschichte der neueren Philosophie. II. S. $63 ; 636$. 
finden würde, mag hier dahingestellt bleiben. Das erste gegen die Betrachtung anzuführende Argument ist dieses, dass Kant

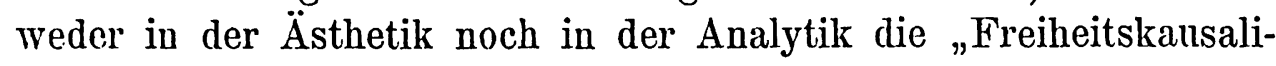
tät" aufgestellt hat, und es scheint doch für Kant von Bedeutung sein zu müssen, das Wort "Ursache", wo es in der Amphibolie der Reflexionsbegriffe und im 4. Paralogismus plötzlich eine ganz andere Kausalität als die vorher entwickelte bezeichnen sollte, näher zu präzisieren, um Missverständnissen vorzubeugen. Ebenfalls hätte Kant nach dem Erscheinen des Jacobischen Einwurfes kurz und gut dies erlösende Wort „Freiheitskausalität" sagen können, das den Streit in ein anderes Gebiet verlegt haben würde. Dies that Kant aber nicht, und zwar in enger Verbindung mit dem entscheidenden Argument gegen die Betrachtung. Kant thut es nicht, weil er das Wort Freiheit nur von der kausallosen Willensbéstimmung des Menschen und allein von dieser gebraucht. Die Wirkung des intelligibeln Ich auf das empirische Ich, des homo noumenon auf den homo phaenomenon ist einzig und allein die Freiheitskausalität, das intelligible Ich ist das Einzige in der Welt, das "frei" ist, das ausserhalb der kausalen Notwendigkeit steht. Oder mit den oben gebrauchten Bezeichnungen: die Wirkung des $\mathrm{S}$ auf $\mathrm{Ph}-\mathrm{S}$ (und vielleicht weiter auf $\mathrm{Ph}-\mathrm{O}$ ) giebt die „Freiheitskausalität" an, dagegen nicht die Wirkung des $O$ auf $\mathrm{Ph}-\mathrm{O}$ (und vielleicht weiter auf $\mathrm{Ph}-\mathrm{S}$ ).

Den freien Willen auch in das Objektive einführen, würde heissen, alles der reinen Willkür überlassen, und die Voraussetzung des Dinges an sich in der theoretischen Philosophie war ja gerade die, dass das Ding an sich konstant wirke. ${ }^{1)}$ Überdies ist $\mathrm{zu}$ beachten, dass Kant beständig eine bestimmte Grenze zwischen der theoretischen und der praktischen Philosophie annimmt; erstere bereite dem moralischen Glauben den Weg, der Glaube lasse sich aber nicht zur Beseitigung der Schwierigkeiten in der theoretischen Philosophic gebrauchen. In völliger Ü̉bereinstimmung mit seiner ganzen Grundbetrachtung vermied Kant selbst es, diesen Ausweg zu benutzen.

Selbst wenn man nun die Richtigkeit der Erdmannschen Behauptung zugeben wollte, so würde diese den Widerspruch bei Kant doch nicht heben, denn es ist klar, dass auch das

1) Vergl. Drobisch' Kritik von Erdmann („Kants Dinge an sich“. S. $16-25)$. 
Erdmannsche durch Freiheit wirkende Ding an sich in der theoretischen Philosophie mit dem transscendentalen unvereinbar ist. Freiheit heisst: ohne Kausalität; von einem nur problematischen Etwas, das nur als Non-E bezeichnet werden sollte, das vielleicht gar nicht existiert, lässt sich jedoch uibcrhaupt durchaus nicht sagen, es wirke, einerlei ob es gemäss der gewöhnlichen oder gemäss einer anderen Kausalitätskategorie wirken sollte, denn es lässt sich ganz einfach gar nichts dariiber aussagen, und dies muss feststehen, welchen Sinn Kant oder seine Apologeten auch mit dem Worte "Freiheitskausalität" zu verbinden im stande sein möchten. Das transscendentale Ding an sich ist die richtige Konsequenz, welche die kritische Philosophie aus dem Ding an sich der Dissertation zieht - ohne Rücksicht auf die sehr ungeeignete Bezeichnung - und über Kants Bestimmungen gelangt man hier nicht hinweg, obschon Kant selbst - dies leider mittels seiner Verwechselung that. Dennoch hat dieser Rettungsversuch seine Bedeutung, ebenso. wie der Langesche; wir finden hier ein Hervorheben der ethischen Motive und des ethischmetaphysischen Hintergrundes, die auch an vielen Stellen in Kants definitivem theoretischem System ganz deutlich hindurchschimmern, und ich glaube, dass dieses Hervorheben - der apologetischen Tendenz unerachtet - in geschichtlicher Beziehung viel Richtiges enthält.

Der letzte Rettungsversuch im Neu-Kritizismus, mit welchem wir uns beschäftigen sollen, wurde von Riehl angestellt. ${ }^{1)}$ Derselbe bezweckt zweierlei: Erstens behauptet Riehl, das Ding an sich sei ein "denknotwendiger" Begriff, was in der That nur dasselbe besagt wie Drobisch' Argument, „Erscheinung müsse etwas haben, was da erscheine;" im Zusammenhang hiermit kommt dann aber das Neue, das Ding an sich sei nicht die Ursache, sondern der Grund der Erscheinungen, und hierdurch sei Jacobis Einwand widerlegt. Hiergegen ist der Einwurf zu erheben, dass selbst, wenn Kant das Ding an sich als Grund und nicht als Ursache der Erscheinungen auffasste, der Widerspruch dennoch vorhanden sein würde, denn erstens kann die Zeit nicht unberücksichtigt bleiben, ${ }^{2}$ ) und zweitens stimmt schon die Bezeichnung „der Grund der Erscheinungen,“ soll sie überhaupt irgend einen Sinn enthalten,

1) Der philosophische Kritizismus (1876). 'I. S. '423--439.

2) Vgl. Höffding: Geschichte der neueren Philosophie. II. S. 637. 
nicht mit Kants Entwickelung des transscendentalen Dinges an sich überein. Zur Stütze seiner Theorie von der Distinktion zwischen dem Kausalitätssatze und dem "Kausalitäts begriffe“ führt Riehl ein Citat an, welches beweisen soll, dass letzterer auf das Ding an sich anwendbar sei. Es trifft sich so unglücklich, dass dieses Citat aus der "Kritik der praktischen Vermunft" herrührt, wo der homo noumenon, der auch nach Riehls Auffassung von dem Begriffe des Dinges an sich der theoretischen Philosophie verschieden ist, mit hinüberspielt. ${ }^{1}$ ) Das Citat sagt in diesem Zusammenhange denn auch thatsächlich nichts, denn es soll nur die Freiheit erklären, deren Ursache der homo noumenon, nicht das Ding an sich ist. Es steht hier nämlich „auf Dinge als reine Verstandeswesen", die beiden letzten Wörter, denen in diesem Zusammenhange gerade der grösste Nachdruck beizulegen ist, hat Riehl aber durchaus übersehen. Der ganze Zusammeuhang zeigt, dass wir hier mit dem homo noumenon und der Freiheit zu schaffen haben. Die Weise, wie Riehl das Citat zerstïckelt, giebt der Stelle einen ganz anderen Sinn. ${ }^{2}$ ) Selbst wenn Riehl in geschichtlicher Be-

1) Der philosophische Kritizismus. I. 435.

2) Die Stelle lautet bei Kant, Kr. d. prakt. Vern. (Kehrbach) S. 65 -68 vgl. $51 ; 55-65)$ : „Wenn etwas noch fehlt, so ist es die Bedingung der Anwendung dieser Kategorien, und namentlich der der Kausalität, auf Gegenstände, nämlich die Anschauung welche, wo sie nicht gegeben ist, die Anwendung zum Behuf der theoretischen Erkenntn is des Gegenstandes, als Noumenon, unmöglich macht, die also, wenn es Jemand darauf wagt, (wie auch in der Kritik der reinen Vernunft geschehen) gänzlich verwehrt wird, indessen, dass noch immer die objektive Realität des Begriffs bleibt, auch von Noumenen gebraucht werden kann, aber ohne diesen Begriff theoretisch im Mindesten bestimmen und dadurch ein Erkenntnis bewirken zu können

Nun ist der Begriff eines Wesens, das freien Willen hat, der Begriff einer causa noumenon, und dass sich dieser Begriff nicht selbst widerspreche, dafür ist man schon dadurch gesichert, dass der Begriff einer Ursache als gänzlich vom reinen Verstande entsprungen, zugieich auch seiner objektiven Realität nach in Ansehung der Gegenstände ïberhaupt durch die Deduktion gesichert, dabei seinem Ursprunge nach von allen sinnlichen Bedingungen unablï̈ngig, also für sich auf Phänomene nicht eingeschränkt, (es sei denn, wo ein theoretischer bestimmter Gebrauch davon gemacht werden wollte,) auf Dinge als reine Verstandeswesen allerdings angewandt werden könne. Weil aber dieser Anwendung keire Anschauung, als die jederzeit nur sinnlich sein kann, untergelegt werden kann, so ist causa noumenon in Ansehung des theoretischen Gebrauchs der Vernunft, obgleich ein möglicher, 
zichung recht häte, hat or doch offenbar unrecht, wenn er behauptet, hiermit sei filcobis Finwurf zu Boden geschlagen, - der Streit ist in der 'That nur nach einem anderen Gebiete verlegt worden. Sehen wir cinmal davon ab, ob der Rettungsversuch möglich ist, und fragen wir nur, ob Kant wirklich gemeint hat, das Ding an sich sei der Grund (im Gegensatze zur Ursache) der Erscheinungen. Riehl sagt hier, "Kant bezeichne das Ding an sich als Grund der Erscheinungen "; ${ }^{1}$ ) wäre es Ursache oder Substanz, so muisste es zeitlich oder räumlich erkennbar sein. Um diese Behauptung zu stiitzen, führt Riehl ein einziges Citat an, in welchem von dem transscendentalen Grunde der Weltordnung die Rede ist. Es leuchtet nun ein, dass Kant, wenn er gemeint hätte, clas Ding an sich sei Grund, gerade im Gegensatz zur Ursache, sich gewiss gehütet hätte das Wort Ursache vom Ding an sich zu gebrauchen. Das von Riehl angeführte Citat sagt nichts, weil Kant so oft z. B. Ver. d.r. V. 320 f. vom "Grunde aller Dinge" und dem „allem zu Grunde Liegenden" spricht, ohne dass hierin irgend ein tieferer Sinn zu suchen wäre; ausserdem wird in der transscendentalen Theologie, auf die sich Riehls Citat bezieht, mehrmals das Wort U rsache angewandt. Liest man Riehl, so erhält man den Eindruck, Kant habe das Ding an sich als Grund und als weiter nichts bezeichnet. Diese Art des Citierens führt zu Missverständnissen:

denkbarer, dennoch leerer Begriff. Nun verlange ich aber auch dadurch nicht die Beschaffenheit eines Wesens, so fern es einen reinen Willen hat, theoretisch zu kennen; es ist mir genug, es dadurch nur als ein solches zu bezeichnen, mithin nur den Begriff der Kausalität mit dem der Freiheit (und was davon unzertrennlich ist, mit dem moralischen Gesetze, als Bestimmungsgrunde derselben), zu verbinden; welche Befugnis mir, vermöge des reinen, nicht empirischen Ursprungs des Begriffs der Ursache, allerdings. zusteht, indem ich davon keinen andoren Gebrauch, als in Beziehung auf das moralische Gesetz, das seine Realität bestimmt, d. i. nur einen praktischen Gebrauch zu machen mich befugt halte [Die fett.gedruckten 4 Worte sind von mir hervorgehoben].

Daraus macht Riehl durch Verkürzung Folgendes (a. a. 0. 432): "Wenn Etwas (zur bestimmten Erkenntnis) noch fehlt, so ist es die Bedingung der Anwendung der Kategorien und namentlich der der Kausalität auf Gegenstände, nämlich die Anschauung,: . . . indessen doch immer die objektive Realität des Begriff s [von Riehl hervorgehoben] bleibt und dies?r auch von Noumenen gebraucht werden kann. . . Die reinen Begriffe können auf Dinge, als reine Veristandeswesen allerdings angewandt werden." (Vgl. hier S. 211 Linie 5 v. o.)

1) Hervorgehoben von Riehl 1. c. S. 434 . 
Kant thut jenes gerade nicht, und Riehl hätte lieber in einer Note darauf aufmerksam machen sollen, dass Kant an den entscheidenden Stellen, in den Abschnitten, wo das Ding an sich näher entwickelt wird, nicht aber an minder wesentlichen, wo das Ding an sich mit der Theologie in Beziehung gebracht wird, ausdrïcklich und bestimmt das Vort Ursache gebraucht, 1) und dies ist denn auch Kants Meinung trotz aller apologetischen Auslegung. Es ist richtig, dass Kant stets mit dem Gegensatze operiert: das Ding an sich lässt sich nicht erkennen, das Ding an sich muss aber gedacht werden. Im letzteren Satze liegt anders nichts, als: es ist notwendig, dass „Erscheinung etwas haben muss, was da erscheint", und dies ist vernunftgemäss als ein Reales zu denken, sonst sagt der Satz überhaupt gar nichts aus; und dass dies Kants Meinung war, zeigen denn auch die Stellen, wo er noch deutlicher mit dem ersteren Satze bricht.

Eigentlich war es Kants Meinung, eine absolute Grenze aufzustellen, jenseits deren er für die absolute moralische Gewissheit und den freien Willen Raum erhalten könnte, ohne dass die theoretische Vernunft im stande wäre, kritisierend einzugreifen. Dergleichen absolute Grenzen lassen sich in der Wissenschaft nicht aufstellen, ${ }^{2}$ ) die theoretische Vernunft hat im Laufe der Zeit recht kritische Eingriffe in Kants ethisches System gemacht, und nicht einmal Kant selbst hat es vermocht, an seinem absoluten Dualismus und an seinem Programm, nach welchem die theoretische Vernunft nur die intelligible Welt zum späteren Tummelplatz der praktischen Vernunft aufräumen sollte, beharrlich festzuhalten. Immer wieder hat Kant eben in der theoretischen Philosophie die Grenze überschritten; wir haben es hier versucht, die mehr wesentlichen Überschreitungen hervorzuheben, ausser diesen giebt es aber nicht wenige in dem letzten Teile der Kritik der reinen Vernunft (in den Antinomien und der Ideenlehre), deren nähere Erörterung

1) Ich verweise hier auf die Kr. d. r. V. S. 258 (Amphibolie der Reflexionsbegriffe), 315 (4. Paralogismus), 328, 330 (Summe der reinen Seelenlehrè). Wie kann Riehl diese Citate mit seiner kategorischen Äusserung (S. 43t) vereinen?

2) Deshalb entwickelt Spe ncer in den „First principles" das Verhältnis zwischen Religion und Wissenschaft denn auch durchaus falsch. Ich glaube, wir haben hier eine der Stellen in der Geschichte der Philosophie, wo Kants Fehler im Begriffe des Dinges an sich auf bedauerliche Weise wieder zum Vorschein kommt. 
nach den Hervorhebungen gewiss als überflüssig und gar zu weitlïufig betrachtet werden clïrte.

In aller Kürze sei nur folgendes angedeutet. In den beiden ersten Antinomien treffen wir auf eigentliche Weise das Ding an sich an. Wenn Kant behauptet, sowohl die 'Thesen als die Antithesen seien falsch, so beruht dies auf dem Gedlankengang: wir kennen nur Erscheinungen, diese sind als Welt betrachtet an Raum und Zeit unendlich, als Materie absolut teilbar, das sagen die Antithesen; dies lässt sich aber nicht mit Recht sagen, denn wir kennen nicht die Dinge an sich, sondern uur die Materie und die Welt als Erscheinung. Deshalb muss sowohl die Thesis als die Antithesis wegfallen. Das transscendentale Ding an sich sagt hier: weil unsere Erkenntnis den Antithesen recht geben muss, ist es darum doch nicht gewiss, dass es sich wirklich so verhält; es ist sehr wohl möglich, dass es ausserhalb des Bereiches der Erkenntnis eine Grenze der Welt und der Teilbarkeit giebt, - Dies ist. richtig und giebt einen klaren Ausdruck des Dinges an sich. Hierum handelt sich die Frage aber gar nicht. Es gilt, einen Widerspruch in der Erkenntnis nachzuweisen, es gilt, zu zeigen, dass die Thesen mehr Recht und Wert haben denn als blosses, abstraktes und interesseloses Gedankenexperiment. Es ist ebenso möglich, dass es ausserhalb der Welt der Erscheinungen eine Grenze der Zeit und des Raumes und der Teilbarkeit giebt, als es möglich ist, dass im Ding an sich $1+2=4$ sind, eben weil das Ding an sich das "Objekt" für eine ganz andere Erkenntnis als die unsrige ist; dies lässt sich weder bestreiten noch bestätigen; deshalb entsteht aber doch keine Antinonie; gerade weil wir von keiner anderen Erkenntnis als der uns nun einmal bekannten reden können, müssen wir behaupten, dass die Antithesen allein im Rechte sind. Der Fehler steckt darin, dass Kant überhaupt von einer Antinomie gesprochen hat, denn eine solche existiert einfach nicht; wenn Kant so grosse Schwierigkeiten in dem illusorischen Problem erblickte und dasselbe so sonderbar und verwickelt aufstellte, so zeigt dies thatsächlich an, dass er die im Begriffe des transscendentalen Dinges an sich liegende Grenze überschritten hat. Die Thesen geben nämlich die Idee einer absoluten Totalität, diese wird aber nicht in der Welt der Erscheinungeu angetroffen, weil unsere Auffassung nur relativ ist, vernunftgemäss auch nicht innerhalb des. Dinges an sich, weil dieser Begriff selbst problematisch ist, da wir, d. h. 
unsere Erkenntnis, ein solches überhaupt nicht antreffen; wir können ebensowenig etwas ausserhalb unserer eigenen Erkenntnis erkennen, als wir über unseren eigenen Schatten hinwegspringen können.

Dies erleidet in den Antinomien aber eine gänzliche Verschiebung, und das Ding an sich wird mithin eigentlich ein ganz neuer Begriff, der sowohl von dem transscendentalen als dem empirischen und dem ethischen (homo noumenon) verschieden ist. Um diese Verschiebung zu verstehen, muss man meiner Ansicht nach folgendermassen zu Werke gehen: Das empirische Ding an sich, das die Ursache des Materiellen (oder, wo es konsequent und richtig genommen wurde, die Materie selbst) war, erlangte Kant durch seine Grundverwechselung mittels eines Schlusses aus Ph-O auf das transscendentale 0 . Dieses transscendentale Objekt war das empirische + dem transscendentalen Ding an sich. Kant macht nun, da auch Ph-S etwas haben muss, "was da erscheint", den Schluss aus Ph-S auf S, das auf dieselbe Weise entsteht durch Verwechselung des transscendentalen Dinges an sich als das ausserhalb der Grenze der Erkenutnis "Seiende" mit dem empirischen, welches hier zum wirkenden Ich wird. In der Synthese erblickte Kant das Merkmal des Bewusstseins, und somit wird diese Synthese transscendent, was wieder heisst, dass der Begriff des Dinges an sich auch das der Form zu Grunde Liegende wird. Hierdurch entsteht eine vollständige Verwechselung, nun rührt auch die Form des Raumes vom Ding an sich her. Kant legt dem Raume eine gewisse Objektivität in der Welt der Erscheinungen bei, nämlich im Gegensatz $\mathrm{zu}$ inneren Zuständen wie Traum und Sinnesbetrug, was sich mit dem transscendentalen Idealismus sehr wohl vereinen lässt. ${ }^{1)}$

Sowohl wo Kant das Ding an sich für das dem Psychischen und dem Materiellen zu Grunde Liegende hält, als wo er meint, sowohl der Stoff als die Form der Erkenntnis rühre vom Ding an sich her, überschreitet er die Grenzen der Erkenntnis. Es ist wichtig, diese beiden Gesichtspunkte auseinander zu halten. Die Formen der Erkenntnis erreichen wir durch die Untersuchung des Apriorischen unserer Erkenntnis, der notwendigen Voraussetzungen der Erkenntnis. Was nicht hierunter gehört, ist der Stoff der Erkenntnis. Der Gesichtspunkt, aus welchem dieses Problem be-

1) Kr. d. r. V. S. 55-56; 73-74; 318 u. m. 
handelt wird, mag der streng erkenntnistheoretische heissen. Es leuchtet ein, dass dieses Problem mit dem Problem ron Seele und Körper nichts zu schaffen hat. Dennoch scheint es, als hätte Kant die Gesichtspunkte nicht gänzlich gesondert gehalten, wenugleich er nic den Stoff der Frkenntnis mit dem Stoff als dem Materiellen verwechselt hat (vol. hier S. 209). Dass er bei der Behandlung der beiden Probleme den Begriff des Dinges an sich anwendet, ist schon sehr bedenklich; noch schwieriger wird sein Stand in der Ästhetik. Kant hat Zeit und Raum gar zu selr parallelisiert, hiervon abgesehen scheint es mir jedoch berechtigt, Zeit und Raum als Formen, als apriorische Elemente unserer Erkenntnis zu betrachten. Der streng erkenntnistheoretische Gesichtspunkt kaun natürlich aber nicht zu näheren Bestimmungen der Zeit und des Raumes als solche führen. Dennoch hat Kant durch seinen transscendentalen Idealismus und durch die Konsequenzen, die er aus diesem zieht, z. B. gegen die Theologie, den Raum zu einem bloss Subjektiven gemacht. Soweit ich zu sehen vermag, ist der Gesichtspunkt somit verlassen, der Raum wird nicht konsequent als etwas Apriorisches aufgefasst, sondern zugleich, mit Unrecht, als etwas, das allein im Subjekt und nicht in der Aussenwelt liegt. Ich glaube, dass das Ding an sich auch zu dieser Verwechselung der Gesichtspunkte beigetragen hat, die sehr unglücklich ist, ganz abgesehen davon, dass die Theorie von der Subjektivität des Raumes und der Zeit an und für sich wohl kaum haltbar ist. ${ }^{1}$

Jetzt aber erhält der Raum eine höhere Objektivität im Begriffe des Dinges an sich, wo Stoff und Form ineinanderfliessen. ${ }^{2}$ ) Hierdurch wirkt Kants Formbegriff auf den Stoffbegriff zurück, die Aussenwelt erhält als Ding an sich eine Synthese, der des Subjektes entsprechend. Diese Synthese ist in den Ideen ausgedrückt und in den Thesen der beiden ersten Antinomien dargestellt.

Die Ideen sind kristallisierte Ausdrücke eines stetigen, wogenden Bedürfnisses, zu gewissen Zeiten eine absolute Einheit oder Totalität $\mathrm{zu}$ erreichen, in wissenschaftlicher Be-

1) Mit Bezug auf letzteren Punkt verweise ich auf Kromàns Kritik in "Unsere Naturerkenntnis". Kap. 20.

2) Kr. d. r. V. S. 305; 320-321; 444-445. Höffding hat dies klar entwickelt. („Die Kontinuität im philosophischen Entwickelungsgange Kants". Arch. f. Gesch. d. Philos. Bd. VII. S, 399--402.) 
ziehung sind diese Ideen aber nicht haltbar. Die Metaphysik bricht hier aber wieder bei Kant hervor. Erhebt man Einwürfe gegen die Ideen und die Thesen, so verweist Kant auf das transscendentale Ding an sich und behauptet, man habe kein Recht, sich mit einer Kritik einzufinden, weil man hiermit die Grenze der Erkenntnis überschreite; anderseits überschreitet Kant selbst aber die Grenze der Erkenntnis und bewirkt einen Bruch des Dinges an sich, wenn er die Thesen als Glieder einer wirklichen Antinomie aufstellt und die Ideen in das Ding an sich hineinlegt. ${ }^{1}$ ) Der Begriff des Dinges an sich wird hierdurch ein ganz anderer. Es entsteht wieder der leere Substanzbegriff der alten Metaphysik, jedoch mit einem dem Ding an sich als $\mathrm{S}$ entnommenen Plus, als die grosse, umfassende, abschliessende Weltsubstanz (S-O), die in der Ethik als die moralische Weltordnung sogar noch das moralische Plus erhält, ebenso wie das Ding an sich als $\dot{S}$ in der Ethik sein Plus hat als der freie, soziale Vernunft-Wille.

In der dritten Antinomie entwickelt Kant das ethische Ding an sich. Obschon Kants definitive Ethik, wie verschiedene zerstreute Äusserungen zeigen, 1781 noch nicht völlig fertig war, finden wir hier doch genau dieselbe Entwickelung des homo noumenon, die Kant später in seinen ethischen Schriften näher ausführt. In der :3. Antinomie könne sowohl die Thesis als die Antithesis richtig sein, meint Kant, wenn man erstere für das Ding an sich, letztere für die Erscheinungen gelten lasse. Hierdurch ist der Unterschied zwischen dem Menschen als Ding an sich und dem Menschen als Erscheinung statuiert, und es wird nun die Frage, wie Kant zu diesem ethischen Ding an sich gelangt.

Durch alle merkwürdigen ethischen Entwickelungsstadien Kants ziehen sich als rote Fäden vier eng zusammenhängende Hauptbestrebungen. Kant will die Ethik ganz allgeneingültig machen, er will jeden Anlauf zum Egoismus ausschliessen, und will die absolute ethische Verantwortlichkeit und die Selbstüber-

1) „So wird demnache die Antinomie der reinen Vernunft bei ihren kosmologischen Ideen gehoben, dadurch dass gezeigt wird: sie sei bloss dialektisch und ein Widerstreit eines Scheins, der daher entspringt, dass man die Idee der absoluten Totalität, welche nur als eine Bedingung der Dinge an sich selbst gilt, auf Erscheinungen angewandt hat". S.411, vgl. $501-502$. 
einstimmung des Individuums als das Fundamentale behauptet wissen. Das Erste berwegt Kant, sich in der Ethik von der Psychologic zu entfernen und das grösste Gewicht auf die Metaphysik zu legen, das Zweite dazu, den ethischen Inhalt (das oljektive Prinzip) zu eliminieren und die Ethik intuitiv zu machen; die beiden letzten Punkte werden auf sonderbare Weise miteinander vereint, und namentlich für diese erhält das Ding an sich Bedeutung.

Schon in den „Beobachtungen über das Gefühl des Schönen und Erhabenen" (1764) treffen wir den Gedankengang an, der später mit so grosser Schärfe als metaphysischer Dualismus herrortrat. Kant steht hier auf dem emotionellen Standpunkte der englischen Ethik, kämpft aber für die grosse Bedeutung der strengen Grundsätze der Vernunft auf eine Art, die gegen den anderen Faktor, das Gefühl, fast polemisch wird. Der Dualismus zwischen „Vernunft" und „Gefübl“, zwischen den strengen Grundsätzen und dem unmittelbaren Wohlwollen, ist ein Gegensatz, mit welchem Kant fortwährend operiert, und seit frühester Zeit betrachtet er, selbst wo er das Emotionelle zum Fundamentalen der Ethik macht, misstrauisch das Gefühl, das er für das Irrationale, Unklare, Momentane und Kurzsichtige der Ethik ansieht. Dieses repräsentiert ihm eine Art Augenblicksstandpunkt, und Kant erblickte klar, dass die Einheit und Selbstübereinstimmung der Persönlichkeit eine entscheidende Bedingung jeglicher Ethik ist. ${ }^{1}$ ) Kants Verteidigung der Vernunft und seine Auffassung des Gefühls gehören zu den Punkten, welche die Kontinuität der Kantischen Ethils von deren erstem Stadium an bis zum definitiven System am besten darlegen.

In einem kleinen ethischen Fragment, ${ }^{2}$ ) dessen Abfassung gewiss in die Zeit zwischen der Dissertation und der Kritik der reinen Vernunft zu verlegen ist, ${ }^{3}$ ) haben wir ein ganz eigentüm-

1) Werke (Hartenstein, 2. Aufl.). II. S. 234-240.

2) Reicke: Lose Blätter aus Kants Nachlass. 6. (I. 9-16).

3) Vgl. Höffding: Die Kontinuität des philosophischen Entwickelungsganges Kants. (Arch. f. Gesch. d. Philos. VII S. 461 in der Note.) Derselbe: Rousseaus Einfluss auf die definitive Form der Kantischen Ethik („Kantstudien“ II. Band. S. 11 f.) Foerster: Der Entwickelungsgang der Kantischen Ethik. (1894). S. 39-74. Eine nähere Bestimmung der Entstehungszeit als zwischen 1772 und 1781 wage ich nicht zu geben. So klar Foersters Nachweis ist, dass das Fragment nicht während der Periode der definitiven Ethik geschrieben sein kann, vielleicht nicht einmal nach 
liches Übergangsglied zwischen den Schriften aus den sechziger Jahren und Kants definitivem System. Die strengen Vernunftgrundsätze der "Beobachtungen" sind hier zu einer Vernunfteinheit verdichtet worden. Wie die Synthese die Voraussetzung der Erkenntnis und des Bewusstseins ist, so ist die ethische Synthese, die Übereinstimmung des Individuums mit sich selbst, die ethische Kontinuität des Lebens, eine apriorische Voraussetzung der Ethik. Es ist klar, dass wir hier nur ein formelles Kriterium der Ethik haben; was die neuere Psychologie die „reale Einheit des Bewusstseins" nemnt, wird als ethisches Prinzip aufgestellt, jedoch nicht ethisch bestimmt. ${ }^{1}$ ) Dies steht im Zusammenhang mit dem Intuitionismus in Kants Ethik, mit seinem scharfen Dualismus zwischen dem Begriffe des Egoismus und dem absolut Intuitiv-Altruistischen, und dieser Formalismus bedingt wieder die metaphysische Bestimmung in Kants definitivem System, den Übergang aus der psychologischen in die intelligible Freiheit. Diese ethische Synthese, die reine Spontaneität, wird hier aus der Vernunfteinheit zum Vernunftwillen in Kants definitiver Ethik. Klarer ausgedrückt: wie die „formale Einheit" oder Synthese des Bewusstseins durch den Schluss aus $\mathrm{Ph}-\mathrm{S}$ auf $\mathrm{S}$ zum Ding an sich, transscendent statt transscendental gemacht wird, so wird in der Ethik auf dieselbe Weise die "reale Einheit" in das Ding an sich hineingezogen, wodurch das intelligible Ich entsteht und die intelligible Freiheit die psychologische ablöst. Die Synthese und ihre ethische Analogieform verändern völlig ihren Charakter, nachdem sie sich oben in der 4. Dimension des Dinges an sich aufgehalten haben.

Hierzu kommt in der definitiven Ethik noch eine reale Bestimmung. Unter erneuter Einwirkung von Seiten Rousseaus und in enger Verbindung mit Kants Bemühungen, jeglichen Egoismus auszuschliessen, wird das intelligible Ich sozial bestimmt. Der allgemeine Wille wirkt im Willen des Einzelnen, der Einzelne wird ein Teil einer grossen moralischen Weltordnung, deren prästabilierte

der Kr. d. r. Vern., so schwach ist sein Beweis, dass es nicht viel später als 1773 verfasst sei. Es kommt indes ja wesentlich darauf an, das Fragment geschichtlich in seiner Beziehung zu den Schriften aus den sechziger Jahren einerseits, der Kritik der reinen Vernunft und der definitiven Ethik anderseits zu bestimmen. Es wäre meiner Meinung nach unvorsichtig, nach dem vorliegenden Material eine nähere Bestimmung zu versuchen.

1) Vgl. meine Abhandlung im Archiv f. Geschichte d. Philosophie XVI. Band 2. Heft. 
Harmonie im Ding an sich liegt. Das intelligible und das sozialbestimmte Ich verschmelzen innig miteinander, und dies ist das ethische Ding an sich als homo noumenon, während das formelle Kriterium des Reickeschen Fragments ganz natürlich zurücktritt, wo das Psychologische in der Ethik vom Metaphysischen abgelöst wird. Im intelligibeln Ich, im Ding an sich. liegt das absolute Gute. 1) Der hier entwickelte Prozess findet seine Stütze an dem ganzen unklaren und komplizierten Prozesse, der zu Kants endlichem Freiheitsbegriffe führt.

Kants Freiheitsbegriff in seiner früheren Ethik ist nicht klar; teils hat er diese Unklarheit von Leibniz geerbt, ${ }^{2}$ ) teils war die Aufstellung des Problems durch die Bestimmung des Dinges an sich als Monaden etwas erschwert. Charakteristisch sind hier die Pölitzschen Vorlesungen, deren Abschnitt über die Psychologie gewiss aus der Periode zwischen der Dissertation und der Kritik der reinen Vernunft herrïhrt. ${ }^{3}$ ) Die psychologische und die intelligible Freiheit werden hier nicht ganz getrennt gehalten, weil der Begriff des Dinges an sich sicherlich noch nicht zu solcher Klarheit gelangt war wie das transscendentale Ding an sich in der Kritik der reinen Vernunft, weil die Begriffe „äussere“, „erste“, „fremde“ und „innere" Ursache mehr im Monadenbegriffe verfliessen, und endlich weil anzunehmen ist, dass die psychologische Freiheit aus

1) Auch das radikale Böse, das man sonst im Stoffe zu suchen geneigt sein könnte, in natürlicher Konsequenz des ganzen platonischen Dualismus zwischen homo noumenon und homo phaenomenon (Werke II. S. 11:3 -154). Weil das Ding an sich schliesslich alles verschlingt, und weil Kant durchaus nicht mit dem Stoffe zu operieren vermag - was auch in der theoretischen Philosophie höchlich zur Verwechselung beiträgt $\rightarrow$, und endlich weil er mit richtigem psychologischem Blicke hervorhob, der Grundcharakter sei das einzig Entscheidende, wird das radikale Böse in die Form, in den homo noumenon, in die Synthese hineingelegt, nämlich wo das Gegenteil des ethischen Gesetzes zum höchsten Gesetze gemacht wird. Der erste. psychologische Anfang dieser Auffassung findet sich bereits in den „Beobachtungen" (Werke II. S. 249). Es ist ein ähnlicher Gedanke wie derjenige, welchen Bacon durch seinen "guten Läufer" entwickelt liat Tovum Organum. Opera. 1649. S. 289). J. G. Fichte, bei dem die Bestimmung des Begriffes "Spontaneität" eine andere Richtung einschlägt, setzt gewissermassen den Grundgedanken des Reickeschen Fragments fort ("Versuch einer Kritik aller Offenbarung“". Werke V. S 89 und in den späteren ethischen Schriften).

2) Oevres ed. Jacques. II. S. 96 u. f. Vgl. Schopenhauer: "Die beiden Grundprobleme der Ethik." S. 59.

3) Vorlesungen ed. Pölitz. S. 206-209. 
Kants früheren Schriften vielleicht gerade um diese Zeit ihre klarste Entwickelung erreichte, durch ihre Verbindung mit dem Synthesenbegriffe nämlich, aus welcher der Übergang zum Transscendenten allerdings nur einen einzigen Schritt erforderte. Es stellt sich dar, dass in Kants früheren ethischen Schriften nur von der psychologischen Freiheit die Rede ist, und dennoch ist es wohl keinem Zweifel unterworfen, dass Kant niemals Determinist war, nur gelang es ihm nicht, das Problem klar zum Vorschein zu bringen, weshalb er bei der psychologischen Freiheit stehen blieb; fortwährend stossen uns Änsserungen auf, die eine andere Freiheit andeuten, je schärfer Kant das Problem durchdachte, um so mehr leuchtete es ihm ein, dass er sich nicht mit der psychologischen Freiheit begnügen konnte. Es ist meiner Ansicht nach unzweifelhaft, dass es bedeutenden Einfluss auf das Ding an sich gehabt hat, dass Kant, nachdem er sich das Freiheitsproblem klar gestellt. hatte, aus ethischen Gründen die intelligible Freiheit verfechten wollte. Ohne die Grundverwechselung wäre sein Freiheitsbegriff nicht möglich, und indem schliesslich Stoff und Form ineinander fliessen, waren - ausser dem in Kants latenter Monadenmetaphysik liegenden Motive - gewiss auch ethische Motive von durchaus entscheidender Bedeutung. Die Entwickelung des Freiheitsbegriffes geht Hand in Hand mit der Entwickelung aus dem Emotionalismus in den Intellektualismus.

Die dritte Antinomie glaubt Kant dadurch gelöst zu haben, dass die Thesis für das Ding an sich, die Antithesis für die Erscheinungen gelten sollte, dies ist aber eine falsche Lösung, denn das Problem bezieht sich nur auf Erscheinungen. Hier finden wir deutlich die Verwechselung zwischen dem transscendentalen und dem empirischen Ding an sich (hier als die analoge Form Ph-S, die Kant fälschlich zur Synthese reduziert) als homo noumenon. Wenn Kant sagt, der intelligible Charakter wirke auf dic Aussenwelt, so haben wir offenbar das empirische Ding an sich vor uns, allerdings als das letzte dem Subjekte zu Grunde Liegende und in ethischer Form. Dies ist damit gegeben, dass dasselbe nicht problematisch, sondern existierend ist, und dass es in einer Kausalitätsreihe liegt, wenn auch als Anfangspunkt, als absolut erstes Glied. Wenn Kant anderseits aber behauptet, der -intelligible Charakter stehe ausserhalb der Kausalitätsreihe, so zwar, dass derselbe aus sich allein Reihen erzeugen könne, und wenn er die Kritik durch die Behauptung entwaffnet, als Ding an sich sei der 
intelligible Charakter uiber Anschauungsformen und Kategorien erhaben, und der Begriff der Freiheit enthalte deswegen keinen Widerspruch für den Verstand, da wir uns hier ausserhalb der Grenze der Erkenntnis befänden, so haben wir mithin das transscendentale Ding an sich.

Es ist erstens klar, dass wir auf dem geistigen Gebicte nicht anf dieselbe Weise vom Ding an sich reden können wie auf dem materiellen. Weil die Synthese eine Grundform des Bewusstseins ist, ohne die der Begriff des Bewusstseins nicht denkbar wäre, hat darum die Annahme doch keine Wahrscheinlichkeit für sich, sie sei das Letzte und das Begründende des Psychischen auf dieselbe Weise, wie sich z. B. der Begriff der Energie als das Letzte und Begründende des Materiellen denken lässt. Dies ist ein falscher Analogieschluss, eine Verwechselung des logisch-apriorischen und des psychologischen Gesichtspunktes; auf dem psychischen Gebiete sind ganz andere Prinzipien und Methoden giiltig. Und endlich ist es klar, dass das transscendentale Ding an sich in der Ethik nicht deutlich hervortreten kann, denn es lässt sich überhaupt durchaus nicht auf irgendwelche Weise mit der Ethik in Verbindung setzen. Schon dadurch, dass Kant diesen Begriff wider die Kritik gebrauchen will, hat er denselben zersplittert; dies beruht zum Teil aber wieder auf der erkenntnistheoretischen oder vielmehr metaphysischen Basis, auf welcher Kant seine Ethil errichtet hatte, um zu retten, was er unter der "Allgemeingültigkeit" verstand. Un es kurz zu sagen: wir finden, wo Kant selbst in der Ethik die Freiheit anwenden will, wo der Mensch ethisch handeln soll, eine dem empirischen Ding an sich analoge Form unter dem Namen des Dinges an sich (homo noumenon). Wo Kant aber gegen die sehr berechtigte und naheliegende Kritik die Freiheit behaupten will, zieht er eine dem transscendentalen Ding an sich analoge Form hervor, d. h. er behauptet, die Freiheit lasse sich nicht mit Berechtigung kritisieren, da sie ausserhalb des Gebietes der Kritik und der Erkenntnis liege. Kant meint, das Ding an sich sei aufgeräumter Boden, wegen seiner eigenen Verwechselung ist dies aber falsch. Eine. Kritik der metaphysischen Grundlage der Käntischen Ethik erschien schon ziemlich früh und hat jetzt so häufig stattgefunden, dass man diese grosse Diskussion wohl als abgeschlossen betrachten darf; hier wollten wir von unserem ganz bestimmten Gesichtspunkt aus nur darauf aufmerksam machen, wie der Fehler sich in 
die Ethik verzweigt, und welche Fehlschlüsse den Fehler in die Ethik hineinbrachten, oder vielmehr vielleicht, wie Kants ethische Ansichten zur grossen Grundverwechselung im theoretischen System beitrugen.

Ich glaube nicht, dass man ohne diese Grundverwechselung in stande ist, Kants sonderbare Lösungen des Problems - von dem Verhältnisse zwischen Subjekt und Objekt, mehrere unter der Einwirkung dieser Lösungen stehende Punkte des Systems und die Entwickelung der Kantischen Ethik seit 1770 zu verstehen. Kants unklarer Gedankengang in diesem Problem drängte sich an vielen Orten störend in Kants grösstes und genialstes Werk auf dem Gebiete der Erkenntnistheorie: in die Entwickelung des Apriorismus. Das Ding an sich sammelt alle metaphysischen Anläufe bei Kant und erzeugt trotz alles Kritizismus eine Metaphysik, die zuguterletzt nicht viel besser wurde als die altc, von Kant zersetzte. Stoff und Form, Synthese und Materie, Monade und Substanz, Freiheit und Kausalität, Vernunft, Gewissen und Ville, das absolute Gute und das radikale Böse, alles Erkennbare und sogar die Negation der Erkenntnis, alles fliesst schliesslich im Begriffe des Dinges an sich incinander, der die Grenze aller Dinge sein sollte, der in der That aber alles verschlingt, um darauf in seiner 4. Dimension die Begriffe umzukehren und die leeren Worte ihren Spuk treiben zu lassen. In der Wissenschaft ist das leere Wort das Gefährlichste, denn es ist zähe wegen seiner eigenen Leere; es ist das Gespenst des Begriffes, und so schwer es sein soll, Gespenster ums Leben zu bringen, ebenso schwer ist es, das leere Wort zu töten. Das Wort „Ding an sich" hat in der Wissenschaft sehr grossen Schaden angarichtet, gerade weil es ein unklares Wort ist, dem nicht beizukommen war; durch dieses hat die Philosophie der Theologie wider sich selbst Waffen in die Hand gegeben, die ohne Kants Verwechselung sich gegen die Theologie gerichtet haben würden, durch dieses wurde die Philosophie selbst auf die sonderbarsten Spekulationen geführt, die jhr nicht zum Vorteil gereiclst haben. Es war hier unsere Aufgabe, die Kritik des 18. Jahrhunderts wieder gegen die Apologetik des 19. Jahrhunderts hervorzuziehen und durch eine geschichtliche und kritische Erörterung ein wenig zur Zerstreuung der Nebel beizutragen, die sich um den Begriff des Dinges an sich gelagert hatten. 


\section{Note zu S. 209.}

Vaihingers Gedankengang ist in Kürze der, dass Kant durch die Aunahme einer Aussenwelt oder Materie an anderen Punkten mit sich selbst in Widerspruch gerate. Er stïtzt sich hierbei auf liants Widerlegung des Idealismus.1) zcigt indes, dass der Widerspruch auch in der ersten Auflage der Kritik der reinen Vernunft vorkomme, und dass Kants Stellung zum Idealismus eine Verschiebung erleide, indem dieser in den Prolegomena (1783) und in der 2. Auflage der Kritik der reinen Vernunft das Ding an sich (0) mit in den Kampf gegen den Idealismus heranziehe, in welchem früher nur von Mraterie (Ph-O) die Rede gewesen sei. Ich glaube, dass Vaihinger hier Kant unrecht thut; es giebt Widersprüche genug bei Kant, aber nicht so, wie Vaihinger sie sieht. Der Zusammenhang bei Kant (Kr. d. r. V. S. 311-321) ist folgender: Er lobt den skeptischen Idealismus, weil dieser langsam und vorsichtig zu Werke gehe und somit auch entschieden davor warne, äussere Gegenstände im Raume mit dem Ding an sich zu verwechseln. Das Berechtigte des Idealismus liege zu allen Zeiten darin, dass er einschärfe, alle Erkenntnis sei phänomenal, wenn man bei dieser Behauptung auch nicht stehen bleiben dürfe. Kant sondert auch zwischen $\mathrm{Ph}-\mathrm{O}$ und $\mathrm{Ph}-\mathrm{S}$ und tritt entschieden für die Berechtigung dieses Schrittes ein. Sowohl die Aussenwelt als unsere Vorstellungen sind aber Erscheinungen: „Wenn wir äussere Gegenstände für Dinge an sich gelten lassen, so ist schlechthin unmöglich zu begreifen, wie wir zur Erkenntnis ihrer Wirklichkeit ausser uns kommen sollten, indem wir uns bloss auf die Vorstellung stützen, die in uns ist. Denn man kann doch ausser sich nicht empfinden, sondern nur in sich selbst, und das ganze Selbstbewusstsein liefert daher nichts, als lediglich unsere eigenen Bestimmungen. Also nötigt uns der skeptische Idealismus, die einzige Zuflucht, die uns übrig bleibt, nämlich zu der Idealität aller Erscheinungen zu ergreifen." (Kr. d. r. V. S. 319-320). Die kurze und klare Meinung ist hier also die: der skeptische Idealismus zwingt uns zu dem Eingeständnisse, zu dem wir auch auf anderen Wegen gelangen, dass unsere Erkenntnis phänomenal ist. Über diese Äusserung von Kant schreibt Vaihinger nun (Strassb. Abh. S. 121): „Das ist deutlich gesprochen, so deutlich

1) „Zu Kants Widerlegung des Idealismus" in den "Strassburger Abhandlungen zur Philosophie" (Ed. Zeller zu seinem 70. Geburtstage), Freiburg u. Tübingen (Mohr) 1884. 
wie möglich. Der skeptische Idealismus ist unberechtigt, weil seine Prämisse einer unseren äusseren Wahruehmungen noch (eventuell) entsprechenden Aussenwelt falsch ist: man braucht also nicht auf eine solche zu schliessen. Die ganze Aussenwelt geht in unseren Vorstellungen auf. Unsere äusseren Vorstellungen sind die Aussenwelt, die Aussenwelt ist unsere Vorstellung." Das Citat aus Kant scheint doch nicht "deutlich genug“ gewesen zu sein, denn indem Vaihinger also auf Kants vorhergehende Äusserungen (Kr. d. r. V. S. 312) über Schlüsse auf die Aussenwelt verweist, welche Schlïsse Kant ausdrücklich als Schlüsse widerlegt, indem er die unmittelbare Gewissheit von der Realität der Aussenwelt behauptet (wobei er allerdings den psychologischen mit dem erkenntnistheoretischen Gesichtspunkt, das berechtigte „Gefühl der Urfrische“ als psychologische Urthatsache mit der erkenntnistheoretischen Berechtigung dieser Annahme verwechselt), bekommt er aus Kants Worten den ganz entgegengesetzten Sinu heraus. Nach Vaihinger sollte nämlich bei Kant der skeptische Idealismus durch den dogmatischen widerlegt worden sein. „Er hat ja den skeptischen Idealismus, welcher behauptet, man mïsse das Dasein der Materie erst beweisen, damit widerlegt, dass er dieses Dasein als ein Vorurteil aufdeckt." Das höchst Sonderbare ist aber, dass Kant selbst dieses „Vorurteil" hegt, und zwar nicht nur stillschweigend, denn der ganze Abschnitt bezweckt den Nachweis, dass der skeptische Idealismus unhaltbar sei, weil wir die unmittelbare Gewissheit einer phänomenalen Aussenwelt hätten. Aus guten Gründen wendet Kant nicht den dogmatischen Idealismus wider den skeptischen an, er verficht hier den empirischen Realismus, und es ist klar, dass ihm die Widerlegung des skeptischen Idealismus die Hauptsache sein musste, denn die Widerlegung desselben führte der Natur del Sache gemäss auch die Widerlegung seiner outrierten Form, des dogmatischen Idealismus, herbei, wogegen eine Widerlegung des dogmatischen Idealismus keineswegs die Widerlegung des skeptischen zu bedingen brauchte. Der ganze Abschnitt bei Kant bczweckt, die Realität der Aussenwelt als unmittelbar sicher darzulegen, in Gegensatz zum skeptischen Idealismus, der dieselbe bezweifelt, und zum dogmatischen, der sie leugnet - das liann keine Auslegung wegbringen. Dies steht in direktem Widerspruch mit Vaihingers Auffassung, und es stellt sich ihm denn auch eine Schwierigkeit ein. Er greift nun zu dem Mittel, dass er Kants Worte, wo dieser sich am deutlichsten und direkt über das Problem 
ron der Realität der Aussenwelt ïussert - zwar aber in absoluter und enger Übercinstimmung mit dem ganzen Abschnitte ans dem Zusammenhang herausgerissen in einem besonderen Kapitel mit der Überschrift: „Eine sonderbare Stelle in der Widerlegung des problematischen Idealismus" bespricht (Strassb. Abh. S. 121 u. f.). Kants eigenen Worten zuwider sagt Vaihinger: „Dinge an sich nimmt Kant an, welche Berkeley nicht statuierte; aber das Dasein der Materie lengnet er, das Berkeley auch gelengnet hatte." Das thut Kant aber gerade nicht, die Widerspriiche bei ihm stammen vor allen Dingen daher, dass er das empirische und das transscendentale Ding an sich mit einander verwechselte, keines derselbeu hat er aber jemals geleugnet. Es ist ja eben ein Vorzug bei Kant, dass er einsah, der empirische Realismus müsse hinzukommen, sogar zum transscendentalen Idealismus. Allerdings muss Vaihinger von seiner Auslegung aus sagen, Kants Gedankengang werde "undeutlich, unklar und geradezu rätselhaft", und das Kapitel damit schliessen, dass er zum dritten Mal ausruft: „Wie ist diese seltsame Desavouierung möglich?"

Die Antwort liegt nahe zur Hand: Kant hat sich hier durchaus nicht selbst desavouiert; es entsteht uns dann aber die Frage, wie Vaihinger dazu gekommen ist, diesen Widerspruch aufzustellen, und durch seine Auslegung das Gegenteil von dem herauszubekommen, was meiner Ansicht nach in Kants Worten enthalten ist. Vaihingers Kritik beruht in der That darauf, dass er Kant missverstanden hat. Wenn Kant sagt, die Aussenwelt sei phänomenal, so meint er hiermit, dass sic stets unter bestimmten Formen aufgefasst werde, welche subjektiv seien, oder klarer aus- gedriickt, es liege in der eigenen Natur der Erkenntnis, dass ein Objekt, welches nicht das Objekt eines Subjekts sei, kein Objekt sei. In diesen Sinne lässt sich selbstverständlich - und mit vollem Rechte - sagen, alles sei subjektiv. Hier begeht Vaihinger nun aber, den Fehler, dies damit źn identifizieren, dass alles nur subjektiv sei (mit dem Vorbehalt, dass das Ding an sich (0) zuriickbleibe). Demnach muss man - trotz der subtilen geschichtlichen Erklärung, die Vaihiuger mittels des unbewusst schaffenden transscendentalen Ich giebt - zu der Auffassung kommen, dass Kant selbst (wo er konsequent ist) der Anschaunng gehuldigt habe, gegen die er entschiedén polemisiert, und die er selbst dadurch ausdrückt, dass alles nur Schein, Einbildung und 
Traum sei. Es ist aber ein grosser Unterschied dazwischen, ob alles subjektiv (d. h. als Erscheinung) aufzufassen ist, oder ob alles nur subjektiv ist, und man möge den Idealismus die richtige Konsequenz von Kant werden lassen oder nicht, oder man möge eine weniger wesentliche Schwenkung in Kants Auffassung aus der 1. zur 2. Auflage der Kritik der reinen Vermunft behaupten wollen oder auch nicht, so ist so viel doch durchaus gewiss, dass Kant ein Objektives in der Welt der Erscheinungen verficht.

Vaihingor führt zweiStellen aus Kant an, die sich wie A zu Non-A verhalten sollten (Strassb. Abh. S. 131-132). Die eine lautet: „Nun sind alle äusseren Gegenstände (die Körper) bloss Erscheinungen, mithin auch nichts anderes, als eine Art meiner Vorstellungen, deren Gegenstände nur durch diese Vorstellungen etwas sind, von ihnen abgesondert aber nichts sind;“ die andere: "Also ist die Wahrnehmung dieses Beharrlichen nur durch ein Ding ausser mir und nicht durch die blosse Vorstellung eines Dinges ausser mir möglich." Diese beiden Stellen stehen durchaus nicht im Widerspruch mit einander. Im ersteren Satze sagt Kant, alle äusseren Gegenstände seien Erscheinungen, was gerade heissen will, dass sie von einem Subjekt aufgefasst werden, und folglich sind sie nichts anderes, als "einc Art meiner Vorstellungen", denn was nicht Vorstellung ist, was ausserhalb der Welt der Erscheinungen liegt, ist gerade das transscendentale Ding an sich, das kein .Objekt ist. Innerhalb der Welt der. Erscheinungen sondert Kant nun, was er durch letzteren Satz ausdrückt, zwischen zwei Arten von Vorstellungen ("Vorstellung" hier im weiteren Sinne genommen, mit dem Begriffe des Phäuomenon identifiziert, wie dies auch im ersten Satze der Fall ist). Wir haben erst das objektive "Ding“ (Ph-O) und darauf die blossen Vorstellungen (Vorstellungen in engerem Sinne; die subjektiven Zustände), und diese Sonderung betrachtet Kant als notwendig nach dem Zusammeuhang, dem die Citate entnommen sind, und dem zufolge die Zeitbestimmung etwas Festes ausser uns in der Welt der Erscheinungen voraussetzt. Ganz davon abgesehen, ob letzteres richtig ist, leuchtet es also doch ein, dass wir hier keinen Widerspruch vor uns haben; alles ist Erscheinumg, in der Welt der Erscheinungen müssen wir aber zwischen dem Objektiven und dem Subjektiven unterscheiden. Ich bin nicht in stande, Schwierigkeiten an diesem Punkte zu erblicken, der mit allen fundamentalen Anschauungen Kants in enger Übcreinstimmung steht. Die Grundverwechselung bei Kant ist in 
Vaihingers Augen also die, dass er sowohl das transscendentale (O) als das empirische Ding an sich (Ph-O) habe und uiberdies behaupte, letzteres sei nur subjektiv ( $\mathrm{Ph}-\mathrm{O}=\mathrm{Ph}-\mathrm{S})$. Ich glaube den tiefsten Grund, weshalb Vaihinger zul dieser Meinung kam, weshalb er das Verhältnis zwischen dem Begriffe "Erscheinung“ und dem Begriffe „nur subjektiv“ ( $\mathrm{Ph}$ und $\mathrm{Ph}-\mathrm{S}$ ) nicht klargelegt hat, in seiner Auffassung des Kantischen Begriffes des Dinges an sich zu finden. Dics ausser Betracht gelassen muss man aber mit Bezug auf die von Vaihinger in seiner Abhandlung citierten Stellen (Strassb. Abh. S. 134-138) ganz entschieden behaupten, dass er dadurch, dass er fortwährend, häufig ïberdies ausser Zusammenhang, das Wort "Vorstellung“ einer sehr gesuchten Auslegung unterwirft, zu dem Resultat gelangt, die Naterie oder dic Aussenwelt sei gleich der „blossen Vorstellung“; dadurch dokumentiert er aber, dass er selbst "alles sei nur für ein Subjekt“ mit „alles sei nur Subjekt" verwechselt. Es folgt von selbst, dass Vaihinger auch zu dem Resultat kommt, der "Widerspruch"bei Kant finde sich ebenfalls in der 1. Auflage der Kritik der reinen Vernunft. Diese Verwechselung muss natïrlich der Grundlage seiner weiteren Kritik von Kants Verhältnis zum Idealismus eine schiefe Stellung geben.

Besonders klar tritt dies hervor, wo Vaihinger eine Verschiedenheit der Argumentation gegen den Idealismus vor und nach der Göttinger Recension 1782 statuieren will. Vaihingers Auffassung ist folgende: In den Prolegomena (1783) bezieht Kant den "wirklichen Idealismus" auf das Ding an sich, und während er 1781 den Idealismus als diejenige Richtung bezeichnete, welche die Materie leugne, polemisiert die 2. Auflage (1787) in der "Widerlegung des Idealismus" scheinbar allerdings gegen den skeptischen, in Wirklichkeit aber gegen den dogmatischen Idealismus. So wie Vaihinger die Sache aufstellt und zu beweisen glaubt, ist dies nicht richtig (Strassb. Abh. S. 124-134). In den Prolegomena finden wir in der Anmerkung II (Reclam S. 67) genau denselben Gedankengang wie in der 1. Auflage der Kritik der reinen Vernunft. Der Idealisnus ist hier diejenige Richtung, welche der Aussenwelt Realität abspricht. 'Durch die Göttinger Receusion belehrt, setzt Kant in der Aumerkung III (Prolegomena S. 72) aber hinzu: „Denn dieser von mir sogenaunte Idealismus betraf nicht die Existenz der Sachen (die Bezweiflung derselben aber macht eigentlich den Idealismus in rezipierter Bedeutung aus), 
denn die zu bezweifeln ist mir niemals in den Sinn gekommen, sondern bloss die sinnliche Vorstellung der Sachen ..." Das Ding an sich steht für Kant so fest und sicher da, dass er es nicht eimmal der Mühe wert findet, gegen die Richtung zu polemisieren, der die Absurdität beifallen könnte, dasselbe zu leugnen. $\mathrm{Er}$ polemisiert einerseits gegen diejenigen, welche das Ding an sich, als Geist oder Materie, zu etwas Bekanntem machen wollen (Kr. d. r. V. S. 319-321), anderseits aber auch nur gegen diejenigen, welche das empirische Ding an sich leugnen. Mit vollem Rechte konzentriert Kant seine Aufmerksamkeit auf das Verhältnis zwischen dem Objektiven und dem Subjektiven in der Welt der Erscheinungen. In der 2. Auflage der Kritik der reinen Vernunft („Widerlegung des Idealismus“ S. 208 u. f.) ist denn auch nicht vom Ding an sich die Rede; Kant wiederholt das Argument aus der 1. Auflage und behauptet, wir müssten in der Welt der Erscheinungen ein Objektives annehmeu. Hier stellt Vaihinger nun die irrige Ansicht auf: in der 1. Auflage ist dieses Objektive die Aussenwelt, die blosse Vorstellung ist, in der 2. Auflage aber eine von unseren Vorstellungen unabhängige Aussenwelt (Strassb. Abh. S: 129 u. f.); hierdurch widerlegt Kant in der 2. Auflage Berkeley - und sich selbst mit Bezug auf die 1. Auflage, obschon er anscheinend gegen den skeptischen Idealismus (Descartes) polemisiert. Dass Kant sich selbst widerlegen sollte, beruht nur auf der oben erwähnten Verwechselung; die Widerlegung des Idealismus ist genau dieselbe wie in der 1. Auflage. Dagegen ist es richtig, dass Kant Berkeley widerlegt, auch hier verhält die Sache sich aber ganz ebenso wie in der 1. Auflage. Auch in der 2. Auflage ist es der skeptische Idealismus, der die Realität der Aussenwelt (Ph-O) bezweifelt, der dogmatische, del dieselbe einfach leugnet. Hätte Kant den letzteren widerlegen wollen, so könnte der erstere offenbar sehr wohl sein volles Recht behalten, während die Widerlegung des ersteren eo ipso auch die Widerlegung des letzteren enthält. Deshalb widerlegt Kant in sofern auch Berkeley, denn dieser ist für Kant derjenige Idealist, der $\mathrm{Ph}-\mathrm{O}$ leugnet, worin Kant seinen Definitionen zufolge auch recht hat (gegen Vaihinger S. 128), da Berkeley Kants eigenen Distinktionen gemäss in seinem Gottesbegriffe wirklich etwas dem Kantischen Ding an sich Analoges hat. Dass die Vorrede zur zweiten Auflage der Kritik der reinen Vernunft auf verworrene Weise das Ding an sich mit Kants Widerlegung des Idealismus in 
Verbindung setzen sollte, möchte Vaihinger gewiss schwer zu beweisen fallen. Es ist als durchaus sicher zu betrachten, dass Kant iiberall, wo er es ver'sucht, den Idealismus zu widerlegen Versuchc, denen er schr grosses Gewicht beilegt - nur gegen diejenige Richtung polemisicrt, welche die Realität der Aussenwelt lengnet (vgl. z. B. Reicke: Lose Blätter aus Kants Nachlass I. 1889. B VII (S. 101). C XIII (S. 168 u. f.). D VIII (S. 103 u. f.). D XI (S. 211 u. f.), die gewiss alle aus verschiedenen Zeitpunkten der 80er Jahre herrühren). Nur uru einem Missverständnisse vorzubeugen, wird das Ding an sich ein einziges Mal in den Prolegomena genannt, aber nicht gegen den Idealismus angewandt; das Leuguen desselben kam Kant gar zu absurd vor.

Nach dem hier Entwickelten wird es von geringerem Interesse sein, zu erörtern, wie Kant nach Vaihingers Meinung geschichtlich zu seinem „Widerspruche" kam, und wie die Realität der Aussenwelt in Kants System nicht als eine Schwäche, als ein „realistischer Rückfall", sondern als eine notwendige und unvermeidliche logische Konsequenz der Kantschen Fundamentalansichten zu betrachten sei. Um kurz zu sein, gelangt Vaihinger hierzu mittels des intelligibeln Ich. Er sondert mit Recht zwischen dem transscendentalen Ich (S), dem empirischen Ich ( $\mathrm{Ph}-\mathrm{S})$, der Aussenwelt (Ph-O) und dem Ding an sich (0). Nun meint er, es fänden bei Kant zwei Vorgänge statt: Wir erhielten Affektionen sowohl aus 0 als aus $\mathrm{Ph}=\mathrm{O}, \mathrm{O}$ wirke aber auf das transscendentale, $\mathrm{Ph}-\mathrm{O}$ dagegen auf das empirische Ich. Das Resultat des ersteren Vorgangs sei die gesamte Welt der Erscheimungen (Ph), während das Resultat des letzteren Vorgangs die konkreten Empfindungen, „Erscheinungen von Erscheinungen" $(\mathrm{Ph}-\mathrm{S} \times \mathrm{Ph}-\mathrm{O})$ seien. Die Aussenwelt habe nun Realität in Beziehung auf das empirische Ich, ausserhalb dessen sie liege, nicht aber in Beziehung auf das transscendentale Ich, welches - unbewusst wie Schopenhauers Weltwille - dieselbe geschaffen habe. Das transscendentale Ich schaffe mithin bei Kant einen Idealismus, der einen Realismus umschliesse. (Strassb. Abh. S. 145-146). Für unser empirisches Ich seien Raum und Kausalität aposteriorisch, für unser transscendentales Ich aber apriorisch. Wenn alles Erscheinung: sei, so bedeute dies also: für das transscendentale, dagegen nicht für das empirische Ich. Gegen diese Entwickelung von Vaihinger werden sich verschiedene Einwürfe crheben lassen, ganz davon abgesehen, dass die Verwirrtheit bei Kant inbetreff des Begriffes des Dinges 
an sich unvermindert bleibt, und dass der "Widerspruch“, den Vaihinger kritisiert, eigentlich dieser weitläufigen Genesis mit dem transscendentalen Ich als deus ex machina gar nicht benötigt ist. Erstens giebt Vaihinger selbst an, das transscendentale und das empirische Ich seien untrennbar miteinander verbunden.

Schärfer ist dies so auszudrïcken: In der theoretischen Philosophie ist es überhaupt unmöglich, die Grenze zwischen dem transscendentalen und dem empirischen Ich zu ziehen. Die in der Synthese gesammelten Formen sind transscendental, d. h. sie sind die apriorischen Voraussetzungen der Erkenntnis. Psychologisch lässt sich Kants Distinktion zwischen Stoff und Form dagegen nicht wie in der Erkenutnistheorie behaupten, und wo Kant die Betrachtung. auf das Psychologische erweitert, wird das transscendentale Ich als etwas von dem empirischen Ich Gesondertes, Verschiedenes und Unabhängiges geschaffen, d. h. wir erhalten ein transscendentes Ich, die Synthese wird zum Ding an sich gemacht. Rein erkenntnistheoretisch betrachtet sind die Formen apriorisch, infolge Kants Bestimmungen der Begriffe der Erscheinung und des Dinges an sich (als des transscendentalen) müssen sie aber zugleich phänomenal sein; mittels eines Fehlschlusses gelangt Kant zum Ich als dem Ding an sich und zerstört mithin seinen eignen Apriorismus. In der theoretischen Philosophie ist es absolut unmöglich, die Grenze zwischen dem transscendentalen Ich (als Ding an sich, nicht erkenntnistheoretisch als dem Apriorischen der Erkenntnis aufgefasst) und dem empirischen Ich zu ziehen. Der Fehlschluss findet sich, wie oben entwickelt, bereits in Kants theoretischer Philosophie; mit dem transscendentalen Ich als Ding an sich operiert er aber erst, wo das Ethische die Grenzscheide steckt. Dies ist ganz einleuchtend, denn in der theoretischen Philosophie konnte nichts eine solche Grenzscheide abstecken. Ich glaube, dass man desshalb sehr behutsam sein muss, wenn man das intelligible Ich als Ding an sich in Kants theoretische Philosophie hineinziehen will, und dass man dies nicht ohne zwingende Gründe thun darf. Es ist richtig, dass Kant eine doppelte Affektion annimmt, nämlich aus der Aussenwelt und aus dem Ding an sich, und hierin liegt eben der grosse Widerspruch bei Kant. Dagegen vermag ich den Vorgang zwischen dem transscendentalen Ich (S) und dem Ding an sich (O) nicht $z u$ finden, der bei Kant die ganze Welt der Erscheinungen schaffen sollte:' Gegen diese Annahme gilt es erstens, dass dies eine so flagrante Übertretung von Kants eignen 
Bestimmungen des Begriffes des Dinges an sich enthalten würde, dass man doch glauben sollte, er hätte sich hierdurch seiner ganzen Verwechselung bewusst werden müssen (Strassb). Abh. S. 145); die Ansicht, dic Welt des Kantschen Dinges an sich sollte eine Vechselwirkung zwischen dem intelligibeln Ich und dem Ding an sich (als $(0)$ statuieren, woraus dic Erscheinungen resultierten, wäre mit zwingenden Beweisen zu belegen, um auch nur wahrschcinlich zu werden. Das hat Vaihinger aber nicht gethan. Das von ihm angefïhrte Citat („Widerlegung des problematischen Idealismus". 1788-1791; Werke. 2. Hartenstein III. S. 502-503) scheint mir nur einen Vorgang zwischen $\mathrm{S}$ und $\mathrm{Ph}-\mathrm{S}$ dunkel anzudeuten, der auf dem fehlerhaften Schlusse aus der Form als Voraussetzung der Erfahrung auf die Form als das dem Psychischen real zu Grunde Liegende beruht. Den Vorgang zwischen $S$ und $O$ vermag ich hierin nicht zu finden. Ferner ist $\mathrm{zu}$ beachten, dass in der theoretischen Philosophie Stoff und Form gerade im Begriffe des Dinges an sich zusammenfliessen, so dass $O$ und $S$ ganz dasselbe werden, nämlich die allen Dingen zu Grunde liegende Substanz. Aus der ganzen Ausführung geht hervor, wie man Vaihinger zugeben muss, dass Kant bei weitem nicht klar und frei von Widersprïchen ist, ich glaube aber nicht, dass Vaihingers Entwickelung durchweg dazu beiträgt, über Kants Unklarheit Klarheit zu verbreiten. Kants Unklarheit liegt erstens in seinen Bestimmungen der Aussenwelt oder Naterie, und diese Unklarheit deutet entschieden auf die Grundverwechselung rücksichtlich des Begriffes des Dinges an sich hin; ferner in seiner Bestimmung der Formen, und diese Unklarheit deutet vor allen Dingen auf die Verwechselung des erkenntnistheoretischen und des psychologischen Gesichtspunktes hin, ausserdem aber auch auf die Grundverwechselung in betreff des Begriffes des Dinges an sich. Deshalb werden Kants Bestimmungen des Verhältnisses des Subjektiven (Ph-S) zum Objektiven (Ph-O) so unklar; weit klarer scheinen Kants Bestimmungen der Begriffe "Erscheinung“ und „nur subjektiv" zu sein, obschon die Grundverwechselung mit dem Dinge an sich selbstverständlich auch hier eingreifen muss.

Vortrefflich und klar ist das vorletzte Kapitel bei Vajhinger (Strassb. Abh. S. 150-159). Er führt hier aus, dass Kant zwei Arten der Affektion des Subjekts annimmt, aus dem Ding an sich und aus der Materie (nicht wie vorher zwischen $\mathrm{O}$ und $\mathrm{S}$ einerseits, zwischen $\mathrm{Ph}-\mathrm{O}$ und $\mathrm{Ph}-\mathrm{S}$ anderseits, sondern zwischen $\mathrm{O}$ und $\mathrm{Ph}-\mathrm{S}$ 
und zugleich zwischen $\mathrm{Ph}-\mathrm{O}$ und $\mathrm{Ph}-\mathrm{S})$. Auf Grundlage der letzten Affektion äussert Kant sich auch in seinem Opus posthumum gegen den Idealismus, was unserer Behauptung zufolge in engem Anschluss an alle seine Versuche einer Widerleging des Idealismus von seinen ersten Schriften an bis zu seinen letzten geschieht. (Vgl. z. B. die Dissertation $\$ 11$ und Erdmann: „Reflexionen Kants z. Kr. d. r. V." N. 1195 (S. 340)). Mit Recht hebt Vaihinger hervor, dass die beiden Affektionen, die aus der Materie und die aus dem Ding an sich, in völligem Widerspruch mit einander stehen und sich unmöglich vereinen lassen. Wenn Kant dennoch diese beiden Affektionen hat, so rührt das daher, dass er die Materie als eine unbekannte Substanz mit in den Begriff des Dinges an sich hineinzieht. Dies ist die Hauptsache, und ich glaube, wenn Vaihinger den Widerspruch im Begriffe des Dinges an sich, wie dieser einerseits a usserhalb der Welt der Erscheinungen, anderseits ausserhalb des Subjektiven liegt, gesucht hätte, so würde er es vermieden haben, Kant an denjenigen Stellen unrecht zu thun, wo er selbst nicht erblickt zu haben scheint, dass dieser zwischen dem Phänomenalen und dem bloss Subjektiven sondert. Vaihinger hat diesen wichtigen Punkt Kants transscendentaler Ästhetik übersehen und, soweit ich zu sehen vermag, zu grossen Nachdruck auf Kants Idealismus gelegt, was auch mit der Rolle, die er in seiner geschichtlichen Erklärung des „Widerspruchs" dem transscendentalen Ich zuerteilt, in enger Verbindung steht. Kant verficht in seinem kritischen System unablässig den empirischen Realismus, die Lösung und die Konsequenzen des Problems sind aber an vielen Orten unklar und sich widersprechend geworden, teils wegen der Verschiebung zwischen dem erkenntnistheoretischen und dem psychologischen Gesichtspunkte, teils wegen der Verwechselung hinsichtlich des Dinges an sich. Vaihinger besitzt meines Erachtens in der Besprechung des Problems in Kants Opus posthumum in höherem Grade als die jüngeren Kantforscher den. Schlüssel zum Probleme des Dinges an sich - nur hat er denselben meiner Ansicht nach noch nicht genügend verwertet.

Bemerkung. Auf die vorstehenden Einwendungen gegen meine Auffassung werde ich im dritten und vierten Bande meines Kantcommentars eingehen.

Vailinger. 